Portland State University

PDXScholar

7-1976

\title{
Aging and the Semantic Differential: Semantic Stability in the Measurement of Social Evaluation
}

Marilyn Diane Petersen
Portland State University

Follow this and additional works at: https://pdxscholar.library.pdx.edu/open_access_etds

Digitadrt of the Sociology Commons

comenens know how access to this document benefits you. Network

Logo

Recommended Citation

Petersen, Marilyn Diane, "Aging and the Semantic Differential: Semantic Stability in the Measurement of Social Evaluation" (1976). Dissertations and Theses. Paper 2422.

https://doi.org/10.15760/etd.2417

This Thesis is brought to you for free and open access. It has been accepted for inclusion in Dissertations and Theses by an authorized administrator of PDXScholar. Please contact us if we can make this document more accessible: pdxscholar@pdx.edu. 
AN ABSTRACT OF THE THESIS OF Marilyn D. Petersen for the Master of Arts in Sociology presented July 30, 1976.

Titles Aging and the Semantic Differential: Semantic Stability in the Measurement of Social Evaluation.

APPROVED BY NEVIBERS OF THE THESIS COMMITTEE:
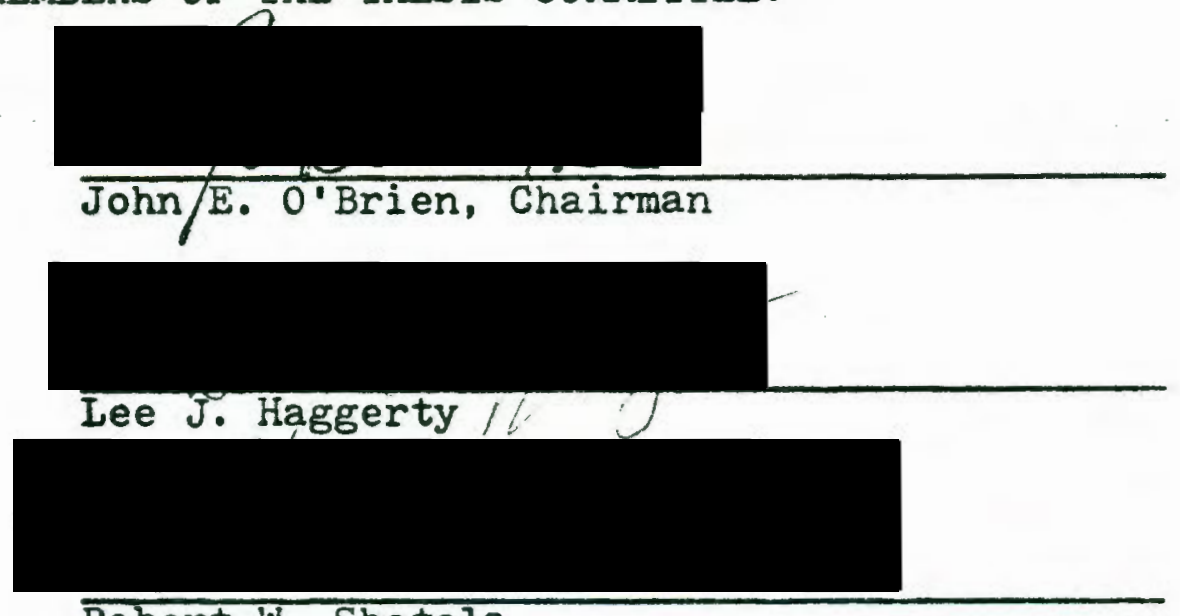

Robert W. Shotola

The purpose of this investigation was to assess the validity of utilizing the same semantic differential test as a measure of social evaluation for persons of different ages. The semantic differential, a rating technique by which judgments of stimuli are made on seven-interval bipolar descriptive continua called "scales," currently receives widespread usage as a measure of attitudes toward aging and the elderly. However, a lack of semantic stability across stimuli and across subjects, known, respectively, as "concept-scale" and "subject- 
scale" interaction, has been found to occur with the technique in various areas of research. That such a lack of stability might occur across stimuli and/or subjects of different ages is suggested by the existence of differences between people of different ages which affect both the appearance and functioning of the individual. These differences derive from the biological aging process, the life cycle process, and the social change process. This study investigated whether such cross-age differences are of sufficient severity to cause people of different ages to be perceived as different classes of stimuli and/or to perceive others as different populations of subjects.

Ratings of eight videotaped stimulus models were made by 60 younger (aged 22 to 32) and 60 older (aged 60 and older) volunteer subjects on a semantic differential test composed of 38 scales. The stimulus models, consisting of four younger and four older adults, were non-actors, unknown to the rating subjects, and presented for one minute in a standardized visual format and without sound. Of the 38 scales used, seven were selected as reference scales from earlier studies, 30 were suggested by a volunteer "generating" sample of 30 younger and 30 older subjects, and one (young/old) was included as a check on the perceived ages of the stimulus models. Scale scores were factor analyzed to establish the underlying factor structure of social evaluation and to ascertain whether it remained stable across stimulus model and subject age levels. Four separate factor analyses were performed -- younger stimulus models/younger subjects, younger stimulus models/older subjects, older stimulus 
models/older subjects, and older stimulus models/younger subjects -- permitting comparisons between the factor matrices for concept-scale and subject-scale interaction.

Three factors were defined by each of the four separate factor analyses of the scales. Factors $A$ and $B$ were found by two different methods of assessing factor similarity (inspection and coefficients of congruence) to be highly similar across both stimulus model and subject age levels; Factor C (a weakly defined factor) was found to be similar only for the older stimulus models across subject age levels. An examination of the scales heavily loaded on each factor for all relevant factor matrices resulted in the interpretation of Factors $A, B$, and $C$ as reflecting Interpersonal Ability, Instrumental Ability, and Propriety, respectively.

This study resulted in findings bearing upon three interrelated areas. First, the data suggest that: 1) older and younger adults constitute qualitatively approximately the same class of stimuli, and 2) older and younger adults constitute qualitatively approximately the same population of subjects. That is, perceptions were based on the same underlying dimensions of meaning regardless of age. Second, the data suggest that two major dimensions of social evaluation are Interpersonal Ability and Instrumental Ability. Comparisons of these two attitudinal dimensions with dimensions from other semantic differential studies revealed striking similarity. Third, the finding of stable scales and replicable dimensions suggests the appropriateness of constructing a cross-age semantic differential for 
social evaluation. Consequently, a 15-scale Cross-Age Semantic Differential for the measurement of social evaluation was proposed. 
AGING AND THE.SEMANTIC DIPFERENTIAI: SEMANTIC STABILITY IN THE MEASUREMENT OF SOCIAL EVALUATION

\title{
by
}

MARILYN D. PETERSEN

A thesis submitted in partial fulfillment of the requirements for the degree of

\author{
MASTER OF ARTS \\ in \\ SOCIOLOGY
}


TO THE OFFICE OF GRADUATE STUDIES AND RESEARCH:

The members of the Committee approve the thesis of Marilyn D. Petersen presented July 29. 1976.

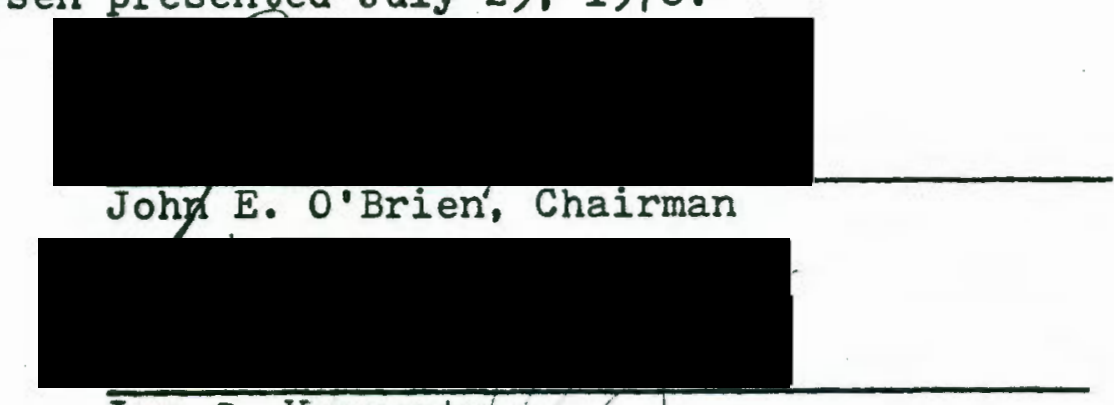

Lee J. Haggerty

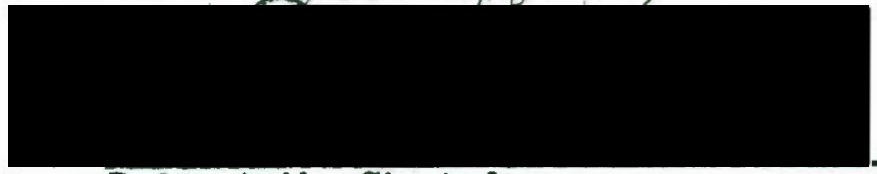

Robert W. Shotola

APPROYED:

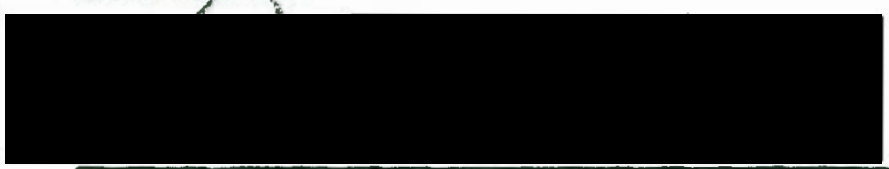

Robert W. Shotola, Chairman, Department of Sociology

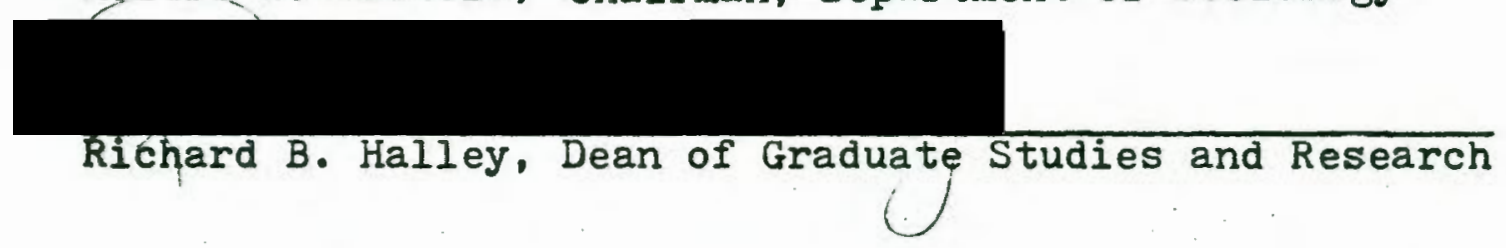


TABLE OF CONTENTS

PAGE

LIST OF TABLES . . . . . . . . • . . . • • vi

LIST OF FIGURES. . . . . . . . • . . . . • v viii

CHAPTER

I PROBLEN: CROSS-AGE VALIDITY OF THE SEMLANTIC

DIFFERENTIAL. . . . . . . . . . . . . 1

Semantic Differential Technique. . . . 2

Basic Elements

Historical Background

Factor Analytic Nethodology

Attitude Measurement

Applications in Social Gerontology . . . 8

Stability Across Stimuli and Subjects. . 12

Stability Across Stimuli

Stability Across Subjects

Focus of Current Investigation . . . . 17

Cross-Age Differences

Cross-Age Semantic Stability

Delimitation of Problem

Summary . . . . . . . . . .

II METHODS : CONSTRUCTING AND TESTING A CROSS-AGE SEMANTIC DIFFERENTIAL . . . . . . . . . 23

Scale Selection. . . . . . . 23

Criteria for Selection

Standard Reference Scales

Generated Scales

Young/01d

Stimulus Selection ......... 
CHAPTER

Age of Stimuli

Stimulus Type and Miode of Presentation

Number of Stimuli and length of Presentation

Standardization of Stimuli

Presentation Order of Stimuli

Data Collection. . . . . . . . 44

Criteria for Selecting Rating Sample

Description of Rating Sample

Rating Procedure

Data Analysis. . . . . . . . 52

Data Preparation

Factor Analysis

Iimitations of the study .......

Size

Scope

Standardization

Ability to Elicit Attitudes

Data Handling

Summary. . . . . . . . . .

III RESULTS: STABILITY AND INSTABIIITY OF A

CROSS-AGE SEMANTIC DIFFERENTIAL . . . . .

Factor Matrices.......... 61

stability. . . . . . . 68

Inspection

Coefficients of Congruence

Summary

Instability. . . . . . . . . .

Factors

Scales

Summary

Young/01d. 
CHAPTER

IV IMPLICATIONS OF STUDY . . . . . . . . . 95

Cross-Age Validity of the Semantic

Differential Technique . . . . . 95

Utilization Implications

Construction Implications

Dimensions of Social Evaluation. . . . 99

The Dimensions

Comparisons with other Studies

Construction of a Cross-Age Semantic

Differential. . . . . . . . . . 104

Scales Applicabie Across Ages

A Cross-Age Semantic Differential

Comparison with the Aging Semantic Differential

Summary. . . . . . . . . . . . 
LIST OF TABLES

TABLE

PAGE

I Example of a Semantic Differential Rating Sheet.

II Scales Suggested by Generating Subjects. . . .

II Most Frequent Responses According to Equal Weight Tally Scheme. . . . . . . . .

IV Fifteen Miost Frequent Responses for Older and Younger Generating Subjects. . . . .

$\checkmark$ Scales Selected for Inclusion in Semantic Differential ......... 40

VI Design of Separate Factor Analyses . . . . . 55

VII Rotated Factor Niatrix, Younger Stimulus Nodels/Younger Subjects... . . . . . 64

VIII Rotated Factor Matrix, Younger Stimulus liodels/OIder Subjects. . . . . . . . .

IX Rotated Factor Matrix, older Stimulus Models/Older Subjects. . . . . . . . .

X Rotated Factor Matrix, Older Stimulus Models/Younger Subjects.........

XI Percent of Variance Accounted for by the Four Factor Analyses . . . . . . . . .

XII Scales Involved with Factor A. . . . . . 70

XIII Scales Involved with Factor B. . . . . . . 76

XIV Scales Involved with Factor C. . . . . . . 79

XV Similarity Percentages . . . . . . . . 80

XVI Coefficients of Congruence . . . . . . . 81

XVII Scales Exhibiting Interaction Tendencies . . . 86 XVIII Concept-Scale Interaction Tendencies . . . . 88 
XIX Subject-Scale Interaction Tendencies....

$\mathrm{XX}$ Nieans and Standard Deviations for Scale

Young/01d ............ 94

XXI Scales Applicable Across Ages. . . . . . 107

XXII Aging Semantic Differential vs. Cross-Age 


\section{IIST OF FIGURES}

\section{FIGURE}

PAGE

1. Miean Scores of Stimulus Model Age Levels

On Scale Young/01d. . . . . . . . . .

2. Cross-Age Semantic Differential for Social

Evaluation. . . . . . . . . . 107 


\section{CHAPTER I}

PROBLEM: CROSS-AGE VALIDITY OF THE SEMANTIC DIFFERENTIAL

Is it valid to utilize the same semantic differential test in investigating the social evaluation of persons of different ages? That is the question investigated by this study. In effect it asks, in regard to the measurement of social evaluation by the semantic differential technique Do persons of different ages constitute different classes of stimuli? and, Do persons of different ages constitute different populations of subjects?

If persons of different ages constitute the same class of stimuli and the same population of subjects, then the semantic differential technique can be viewed as a general measure of social evaluation for persons of different ages. If, however, these conditions do not hold true, the semantic differential technique will need be viewed as age-specific, and constraints will need be placed on its application.

The investigation of this problem was prompted by two factors, 1) the growing popularity among social gerontologists of the semantic differential technique as an attitude measure, and 2) the growing evidence of semantic instability in the technique across stimuli and subjects. These two factors are more fully considered, and the problem stated in more detail, following a brief orienting discussion of the semantic 
differential technique.

\section{SEMANTIC DIFFERENTIAL TECHNIQUE}

\section{Basic Elements}

Since the terminology of the semantic differential technique is to some extent idiosyncratic, definitions of a few key terms are in order:

Stimulus: The phenomenon which is to be rated by the semantic differential technique. "Stimulus" is a general term, including both symbols and objects. In this report, stimuli are indicated by capitalization (e.g., APPLE).

Concept, A stimulus -- consisting of symbols -to be rated. Although "concept" is commonly used in the broader sense of referring to both symbols and objects. in this report it refers to symbols exclusively.

Scaler A descriptive continuum anchored at each end by polar opposite terms. There are seven intervals, or degrees of intensity, between the poles, for example;

$$
\text { good }
$$
bad

Scales are indicated in the test of this report by underlining (e.g., good/bad).

Items The pairing of a scale with a stimulus. For example, a test with 50 scales and 20 stimuli contains 1000 items.

The four basic elements of the semantic differential technique are. 1) a stimulus to be rated, 2) a set of scales on which to perform the rating, 3) a subject to rate the stimulus on the scales, and 4) analysis of the ratings by certain statistical procedures. The stimulus could be a concept, a person, a painting, a piece of music -- whatever the researcher wishes to study. Scales are selected for inclusion in any particular 
semantic differential test from existing sets of standard scales or for relevance to the particular investigation. In other words, the semantic differential is a technique and not an instrument -- there exists no given set of scales or stimuli which construct the semantic differential; instead, scales and stimuli vary in accordance with the objectives of the investigation. Subjects are selected for their relevance to the research question, and analysis of their ratings is usually based on factor analysis.

Table I presents an illustration of a semantic differential rating sheet. Here a stimulus, the concept APPLE, has been rated on nine scales, good/bad, nice/awful, beautiful/ugly, large/small, strong/weak, heavy/light, fast/slow, active/passive, and sharo/dull. In this example, the subject judged APPLE to be quite good, very nice, quite beautiful, quite small, neither strong nor weak, slightly light, slightly fast, very passive, and slightly sharp. The seven intervals between the bipolar descriptive terms are to be interpreted as representing, respectively, very, quite, slightly, neutral (or equal or irrelevant), slightly, quite, and very. Placement of the stimulus on a scale indicates both the direction (e.g., good or bad) and intensity (i.e., how good or how bad) of the subject!s judgment. The name "semantic differential" refers to this rating procedure in which the subject "differentiates" the stimulus on the semantic dimensions which are represented by the scales. 
TABLE I

EXAMPLE OF A SEMANTIC DIFFERENTIAL RATING SHEET

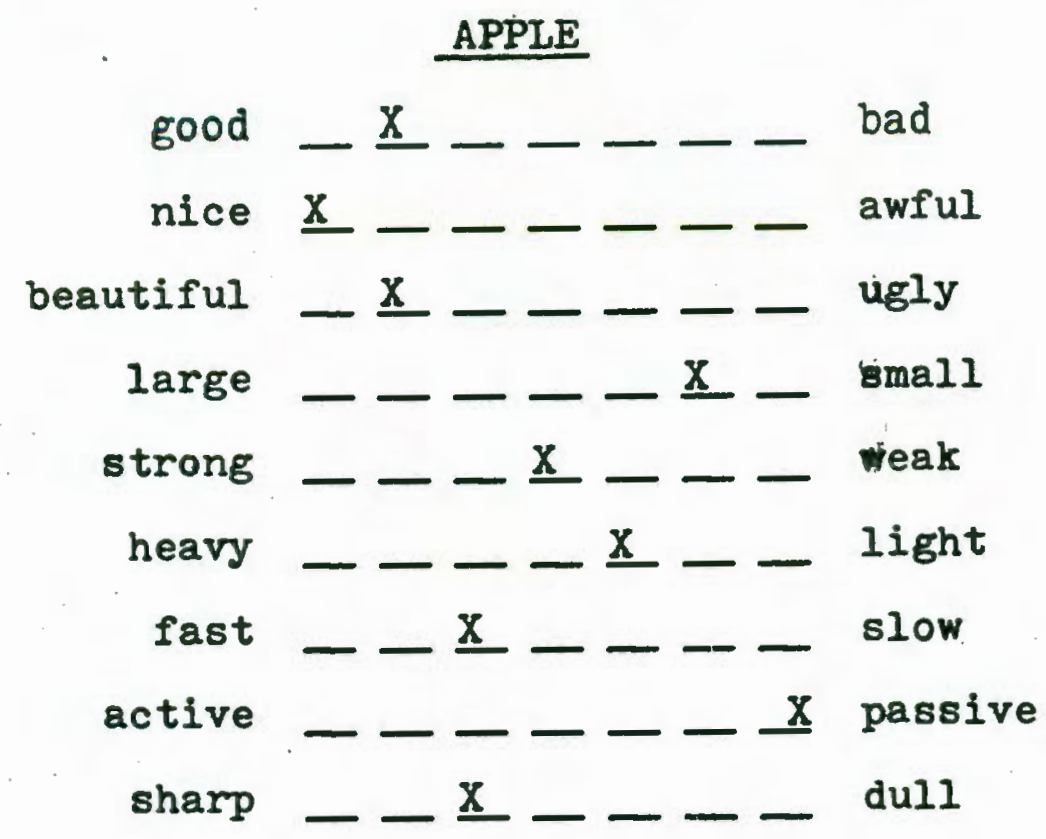

Historical Background

The semantic differential technique was developed during the 1950's by Charles Osgood and his colleagues (Osgood, 1952; Osgood and Suci, 1952, Osgood, Suci, and Tannenbaum, 1957) in an attempt to measure connotative meaning. ${ }^{1}$ As early as 1941 . however, Osgood and a colleague reported having utilized the same rating technique -- i.e., the technique of having subjects rate stimuli on seven-interval bipolar adjective scales -- in two studies of stereotypes, one regarding occupations (Osgood and Stagner, 1941), and one regarding nationalities (Stagner and Osgood, 1941). In a study of changing stereotypes (e.g..

$1_{\text {The meaning of "meaning" in semantic differential studies }}$ is that of an operational definition: "Using this differential, the meaning of a particular concept to a particular individual can be specified quantitatively as a particular point in the multi-dimensional space defined by the instrument (0sgood, 1952, p. 232)." 
pacifist, Russian, dictator, and netrality) during the time period of 1940 to 1942, Osgood and his colleague (Stagner and 0sgood, 1946) suggested the use of the concept of an n-dimensional space to represent the subject's frame of reference.

Three hypotheses underlying the development of the semantic differential technique, made explicit by Osgood in 1952 (p. 228) were:

1. The process of description or judgment can be conceived as the allocation of a concept to an experiential continuum, definable by a pair of polar terms... 2. Nany different experiential continua, or ways in which meanings vary, are essentially equivalent and hence may be represented by a single dimension... 3. A limited number of such continua can be used to define a semantic space within which the meaning of any concept can be specified.

Factor Analytic Methodology

The semantic differential technique, then, was developed primarily as a means of identifying the basic dimensionality of meaning. The procedure involved factor analysis of the numerous bipolar scales -- the experiential continua -- on which the meaning of phenomena might be differentiated in order to find a smaller number of dimensions, $i . e .$. the underlying dimensions of meaning.

In the course of numerous semantic differential studies ${ }^{2}$. Osgood and his colleagues repeatedly isolated the same three major factors during the factor analysis of various sets of

$\mathbf{2}_{\text {These studies are reported in The Measurement of Meaning }}$ (Osgood et al., 1957), which reviewed the history of the first five years of the semantic differential technique. 
scales. ${ }^{3}$ These factors were named: Evaluation (E), Potency (P), and Activity (A). Scales such as good/bad, nice/awful, and beautiful/ugly clustered together to form the Evaluation dimension. The Potency dimension was formed by such scales as large/small, strong/weak, and heavy/light, while the Activity dimension was formed by scales such as fast/slow, active/passive, and sharp/duIl.

Once Osgood's three major factors of meaning had been identified, they were often used for the purpose of test development. That is, scales most strongiy associated with each of the factors were selected for inclusion in tests being constructed to study differences in meaning across stimuli, across subjects, or across time. Through the interpretation and naming of the three major factors, the semantic differential contributed to the formulation of the constructs of an Evaluation dimension, a Potency dimension, and an Activity dimension of meaning. Such constructs could be, and were, utilized as a guide in later investigations.

\section{Attitude Measurement}

Since its development, the semantic differential has also been used to measure attitudes. For example, in 1952, 0sgood (p. 23I) noted the attitude-measurement aspect of the semantic differential technique thusly:

Concepts like GHURCH, LABOR LEADER, STALIN, and MRUMAN have different connotative significance to different people, and the semantic differential can be used to

In addition to these three major factors, several other minor factors were isolated by Osgood and his colleagues: different researchers have also isolated other factors. 
quantify these differences. In this sense, it can be used as a generalized, multidimensional attitude test. By 1957, however, Osgood had equated attitude with the Evaluation dimension of semantic space (Osgood et al., 1957, pp. 189-199). This restricted definition of attitude has since been followed by some utilizers of the semantic differential technique (e.g.. McGinnies, 1970; Taylor, 1971) and not followed by others (e.g., Heise, 1970; Dawes, 1972). The current study does not follow Osgood's equation of attitude with the Evaluation dimension. Rather, attitude is concentualized in this study as a multi-dimensional internal state -- a state of readiness to respond -- which has been learmed through experiences (direct or indirect) with the object of the attitude.

The relationship between attitude and meaning, as defined by this investigator, is quite close. "Meaning" is understood as the interpretation of some phenomenon (e.g., a situation, a person, a word) which specifies what the interpretor's response to the phenomenon ought to be. Meaning is learned; it consists of generally shared meanings and of meanings more specific to the individual (i.e., meanings dependent on the individual's own unique experiential history). Meaning can be thought of as possessing two aspects: denotative meaning (i.e., non-affective descriptive meaning) and connotative meaning (i.e., affective meaning). Connotative meaning may be viewed as the manifestation of an attitude. Thus, the semantic differential, a measure of the connotative meaning of stimuli, is also a measure of attitudes. 
Current usage of the semantic differential as an attitude measurement technique is widespread (see Heise, 1970, p. 236). Indeed, Dawes in his Fundamentals of Attitude Measurement (1972, p. 96) described the semantic differential technique as "one of the most ubiquitous of all the rating scale techniques." It is with the usage of the semantic differential as an attitude measurement technique that this investigation is concerned.

\section{APPLICATIONS IN SOCIAL GERONTOLOGY}

The general popularity of the semantic differential technique as a measure of attitudes is rapidly finding expression in the area of social gerontology. Applications of the technique cover a wide diversity of research interests.

For example, Eisdorfer and Altrocchi (1961, p. 340) utilized the semantic differential technique "to compare attitudes toward old persons with attitudes toward average people and the mentally ill...." Twenty scales representing four factors -- Evaluation, Potency, Activity, and Understandability (from Nunnally, 1961) -- were used to rate eight concepts : AVERAGE MAN, AVERAGE WOMAN, OLD MAN, OLD WOMAN, NEUROTIC MAN, NEUROTIC WOMAN, INSANE MAN, and INSANE WONAN.

Kogan and Wallach (1961, p. 274) used the technique "to examine differences between young and old adults in the evaluation of a diverse array of attitudinal and value-relevant concepts." Concepts rated in the Kogan and Wallach study ( $p$. 272) represented the areas of "work and leisure, majority and 
minority groups, family and interpersonal relations, developmental stages of life, psychological vs. physical attributes of persons, self-concept, and general value orientation." Twenty-five scales formed Kogan and Wallach's original semantic differential (p. 272) -- "scales that were selected so as to represent the three major meaning factors -- evaluation, potency, and activity -- extracted by Osgood and his collaborators." For final comparisons across age and sex samples, however, only seven of the scales (representing an Evaluation factor) were used by Kogan and Wallach.

In 1969 Rosencranz and McNevin proposed a semantic differential for the multi-dimensional measurement of stereotypic attitudes toward the aged -- the "Aging Semantic Differential" -- which offered social gerontologists a set of scales intended to be more relevant to the study of attitudes toward aging and the elderly than were the earlier sets of standard scales. Scales included in the Aging Semantic Differential were selected from a larger pool of bipolar adjective pairs through factor analysis of ratings made on males (aged 20 to 30,40 to 55 , and 70 to 85 ) by subjects aged 17 to 21 years. Three factors -- Instrumental-Ineffective, AutonomousDependent, and Personal Acceptability-Unacceptability -- form the Aging Semant ic Differential.

The Aging Semantic Differential has been utilized by a number of social gerontological researchers. Rosencranz and 
MeNevin (1969, p. 55) used the Aging Semantic Differential to test hypotheses regarding "the effects of differential social experiences upon subject stereotypes of the aging individual." Gordon and Vinacke (1971) compared the actual self concepts of institutionalized elderly persons with their ideal self concepts in a study of dependency of feelings. Cryns and Monk studied the attitudes of the aged toward the young as a function of life satisfaction and filial relationships (1972) and the attitudes of three age groups of adult males -- young. middle-aged, and elderly -- toward the young (1973). Bell and Stanfield (1973, p. 491) compared attitudes toward the young and the old by examining "the influence of age designations upon differential ratings of a stimulus person." And, Naus (1973, p. 229) undertook "to determine the attitudes and stereotypes of a group of college students towards older people, particularly older men" for use as an index of attitudes in the assessment of potential correlates of such attitudes.

Social gerontological studies based on the semantic differential technique but not utilizing the Aging Semantic Differential also continue to be performed. For example, Guptill (1969) proposed to develop a measure of age identification using the semantic differential technique. He utilized seven scales representing three dimensions -- Involvement, Optimism, and Autonomy. The semantic distance between MYSELF and two age designations (MIDDLE-AGED MAN and OLD MAN) formed Guptill's semantic age identification score. 
Back (1971, p. 296), in "seeking a measure ... of evaluation of the self, the discrepancy of the self-image one holds to the way one feels he is seen by others, "made use of a semantic differential composed of the same seven scales used by Guptill. Three concepts were rated in the Back study: WHAT I REALLY AM, WHAT I WOULD LIKE TO BE, and HOW I APPEAR TO OTHERS.

Seltzer and Atchley (1971, p. 226) utilized the semantic differential technique to study "changes in descriptions of old people and things compared with younger people and new things in such [children's] literature from 1870 to 1960." Scales selected for use in the Seltzer and Atchley study represented the Evaluation, Potency, and Activity dimensions at three levels -- psychological, social, and physical.

The technique was utilized by Antonucci (1974, p. 61) "to investigate the relationship between adjustment of aging individuals and their individual values," using scales representing the Evaluation dimension. Ten concepts chosen from Rokeach's value survey were rated in the Antonucci study: FREEDOM, A CONFORTABIE IIFE, AN EXCITING LIFE, A SENSE OF ACCOMPLISHNENT, NATIONAL SECURITY, AMBITIOUS, CAPABLE, OBEDIENT, CLEAN, and INDEPENDENT. Ratings on the ten values were related to a life satisfaction measure.

Nehrke (1974, p. 1) utilized the semantic differential technique "in order to assess actual and perceived attitudes toward death and self-concept within a three-generational family setting," using 21 scales of unspecified dimensionality. 
The seven scales that had been used by Guptill and by Back were also used by Breytspraak and Maddox (1974, p. 3) to measure "the distance between one's self as the person perceives it to actually be (WHAT I REALLY AM) and the self that one would ideally like to be (WHAT I WOULD LIKE TO BE)...." These examples of the utilization of the semantic differential technique by social gerontological researchers illustrate both the growing popularity of the technique in social gerontology and its diversity of application. In some cases, the studies cited indicated cross-age differences in perceptions; in other cases, they indicated cross-age similarity. But these conclusions are questionable unless the assumption of cross-age comparability of the basic structure of meaning is met. Because of the growing number of such research efforts, it is becoming increasingly important to determine whether a lack of semantic stability of the scales across stimuli and subjects poses a validity problem for the technique's usage in social gerontology.

III. STABILITY ACROSS STIMULI AND SUBJECTS

The question of semantic stability of the scales across stimuli and subjects has concerned developers of the semantic differential since the technique's very beginning. For example, in 1952 0sgood ( $p .231$ ) noted the need for what he termed "comparability": stability across stimuli and subjects formed a significant aspect of that criterion:

Can different concepts be compared? To the extent that judgments of different concepts involve the same factor 
structure, any concept may be compared with any other against a single, standardized semantic framework.... Can different individuals be compared? This also comes down to the generality of the semantic factor structure. It is quite conceivable that different classes of people (scientists, ministers, etc.) have somewhat varied semantic structures, differing in the emphasis upon certain factors and interrelationships among them.

\section{Stability Across Stimuli}

"Stability across stimuli" may be thought of as the degree to which semantic differential scales reflect the same basic structure of meaning when used to rate different stimuli. This phenomenon may be clarified by considering the more general association of modifier with stimulus which is experienced in daily conversation. Since the meaning of any modifier is normally learned experientially in combination with stimuli -- and not in the abstract -- it is quite likely that the meaning of a modifier for an individual is not absolute or static across stimuli but rather that it varies with the particular combination of modifier and stimulus. That is, it is quite likely that a modifier possesses multiple meanings for any given individual, of which only some portion would be elicited in any given combination of modifier with stimulus. ${ }^{4}$ Thus, similar stimuli could be expected to elicit stimilar meanings in a modifier, while dissimilar stimuli could be expected to elicit dissimilar meanings.

Since the semantic differential technique is based on the combining of modifiers (the scales) with stimuli, such modifier relativity is of considerable relevance to the technique's users.

4 One portion of such a modifier's meaning might consist of neutrality, i.e., the modifier might be irrelevant to the stimulus. 
Because of modifier relativity, the opportunity for dissimilar combinations of scales and stimuli exist. That is, a given scale, if combined with two sufficiently dissimilar stimuli, becomes, for all practical purposes, two scales. Hence, the scale tough/tender when used to rate the stimulus AUTOMOBILE TIRE might well not be the same scale as when it was used to rate STEAK. In semantic differential terminology, such a lack of semantic stability of the scales across stimuli is known as "concept-scale interaction." As a result of concept-scale interaction, scales may form different patterns of association with each other depending on the stimuli rated. For example, tough/tender might correlate with strong/weak in rating AUTOMOBILE TIRE and with good/bad in rating STEAK. Such different association patterns would be reflected in the factor structure defined during factor analysis. If the association patterns of the scales with each other were substantially different for different stimuli, then it would be inappropriate to compare the stimuli on the basis of a supposedly "single, standardized semantic framework."

Various examples of the concept-scale interaction phenomenon have been reported in the literature, beginning with those offered by Osgood and his colleagues (e.g., Osgood et al., 1957: Tanaka, Oyama, and 0sgood, 1963). For instance, in The Measurement of Meaning, Osgood et al. (1957, p. 326) state:

When we sample across sets of concepts, however, it becomes evident that the scales of judgment and the concepts being judged interact, this interaction influencing the relative weights and even appearance 
of identifiable factors and certainly determining what specific scales contribute to factors.

Further attention was drawn to the concept-scale interaction phenomenon by Brown (1958), Gulliksen (1958), and Carroll (1959) in their detailed reviews of the Measurement of Meaning. Since then, numerous other researchers have also discussed the phenomenon (e.g., Eisdorfer and Altrocchi, 1961; Kubiniec and Farr. 1971; Damell, 1966, 1970; Komorita and Bass, 1967; Heise, 1969: Presly, 1969; Rosenbaum, Rosenbaum, and McGinnies, 1971; Bynner and Romney, 1972; Heaps, 1972; Levy, 1972; Klemmack and Ballweg, 1973; and Smith and Nichols, 1973). Reportings of concept-scale interaction appear to not be limited to any particular class of stimuli but rather to occur generally, in investigations of widely different stimulus classes.

\section{Stability Across Subjects}

The stability-across-subjects question is similar to that of stability-across-stimuli in that both are concerned with the maintenance by the scales of the same meaning across different situations. And, as with stability-across-stimuli, the stability-across-subjects phenomenon derives at least partially from properties of the language learning experience. That is, within any linguistic community, learning environments differ from person to person. Consequently, since the meanings of symbols become defined through an individual's association with the environment, different meanings can become attached to the same symbol by different people. Thus, the meaning of a symbol is relative to the experiential history of a person 
with that symbol. Such differences in meanings may tend to be even more extreme for modifiers than for nouns, since experiences vary more in kind than in essence.

The possibility of considerable variance from person to person in the meaning of a modifier poses the problem of stability across subjects for the semantic differential technique. That is, a scale when used by two sufficiently dissimilar subjects becomes in effect two scales. In semantic differential terminology, such semantic instability across subjects is called "subject-scale interaction." subject-scale interaction results in the formation of different patterns of association by the scales, depending on the subjects performing the ratings. As with concept-scale interaction, the different associative patterns of the scales which result from subject-scale interaction would be reflected in their factor structure and would make inappropriate the equating of subjects on the basis of a supposedly general semantic factor structure.

To date, however, evidence of a lack of stability across subjects has not equaled that indicating lack of stability across stimuli. For example, subject-scale interaction was not found to be a problem by Osgood et al. (1957), Tanaka, Oyama, and Osgood (1963), Darnell (1966), Kubiniec and Farr (1971), Rosenbaum, Rosenbaum, and McGinnies (1971), and Reed (1972). Some evidence of subject-scale interaction, however, has appeared in the literature (e.g., Kogan and Wallach, 1961; Denmark, Shirk, and Riley, 1972; and Heaps, 1972). 
IV. FOCUS OF CURRENT INVESTIGATION

The current investigation was concerned with the validity of the usage of the semantic differential technique as a measure of attitudes toward stimulus persons of different ages by subjects of different ages. The type of attitude studied was that of social evaluation. The question of cross-age validity of the semantic differential technique arises because differences between people of different ages may form the basis for semantic instability in cross-age applications of the technique to measure social evaluation.

\section{Cross-Age Differences}

Age differences manifest themselves in two aspects of relevance to social evaluation -- appearance and functioning. Such age differences may be attributed to, 1) the biological aging process, 2) the life cycle process, and 3) the social change process.

The biological aging process, al though not yet well understood by researchers, can be cited as the source of a number of deteriorative physical changes which occur with increasing age (see Birren, 1959; Atchley, 1972). In general, there occurs a progressive loss of energy, physical abilities, resistance to disease, and recuperative power. Such biological aging occurs at a different rate for different individuals; that is, not every adult of the same chronological age will share the same biological age. 
The life cycle process also produces differences between persons of different ages (see Neugarten, 1968; Kreps, 1971). Individuals enter into and exit from different life stages as they age: especially important are the stages related to family and work. With each new stage in the life cycle come different roles for the individual to play. As the individual becomes socialized into these new roles, the activities and perspectives afforded affect the individual's appearance and functioning.

The social change process creates at the individual level a phenomenon called the "cohort" effect. The cohort effect as conceptualized by such social scientists as Ryder (1965, 1968) and Cain (1967, 1968) involves the experiential history of the aging individual. A cohort, or more precisely, a birth cohort, consists of people who were born at the same time in history. Each birth cohort finds a different environment in which to develop during the different stages of its life than did the cohort which preceded it or the cohort which follows it. The experiences which shape each cohort are different from the experiences which shape other cohorts, and, as a result, each cohort differs from other cohorts to some extent.

As consequences of such cross-age differences, individuals may be age-typed and assigned to age categories by observers; and individuals of different ages may act differently in the evaluation of others. These two types of consequences are suspected of influencing the stability of the semantic differential technique in the cross-age measurement of social evaluation. 
Cross-Age Semantic Stability

Whether a lack of semantic stability on the part of the semantic differential technique constitutes a validity problem in the measurement of the social evaluation of persons of different ages has not yet been determined. If differences between age categories of persons -- how they appear and/or how they act -- are sufficiently strong to cause an individual interacting with representatives of different age categories to learn multiple meanings for his social evaluation modifiers, then concept-scale interaction may indeed be a problem. That is, a given scale when used to rate representatives of two sufficiently different age categories may act as two different scales. Iikewise, if differences between age categories of persons -- i.e., experiential differences in their patterns of interacting with others -- are sufficiently strong to have caused them to develop different meanings for social evaluation modifiers, then subject-scale interaction may be a problem. That is, a given scale when used by representatives of two sufficiently dissimilar age categories to rate other people may act as two different scales, since it has acquired different meanings for the different age categories.

This question of cross-age stability is of practical import to social gerontological utilizers of the semantic differential technique in the measurement of social evaluation because of the method by which such data are commonly analyzed. That is, stimulus persons and/or subjects of different ages are compared with each other on the basis of a supposedly general 
semantic factor structure. Such comparisons are made on a factor's mean score -- that is, on a score obtained by averaging the ratings on scales selected to represent that factor. If, however, the scales do not really represent the ators which they are supposed to represent for all age categories studied, such comparisons can be invalid and misleading. 5

Delimitation of Problem

This investigation was concerned solely with the crossage semantic stability of the semantic differential technique in the measurement of social evaluation. It should be recognized however, that problems other than semantic stability may also affect applications of the semantic differential technique, and that attitudinal areas other than cross-age social evaluation may also be susceptible to semantic instability. Indeed, the problem under investigation is only one of the many which might be explored regarding the utilization of the semantic differential technique as an attitude measure in social gerontology (for examples of other problems, see Osgood et al., 1957; Gulliksen, 1958; Carroll, 1959; Heise, 1969; and Darnell, 1970).

5It should be noted that the question of semantic stability across stimuli and subjects which was of concern in this study consists of differences between the alignment of social evaluation scales for different age categories of stimulus persons and subjects. It does not consist of the differences between the alignment of standard scales on the traditional EvaluationPotency-Activity factors and on the factors defined for the social evaluation of people. Such differences are to be expected (see Carroll, 1959; Heise, 1969), and are not relevant to the question of whether persons of different ages form different classes of stimuli and different populations of subjects in the measurement of social evaluation by the semantic differential technique. 


\section{v. SUMMARY}

The purpose of this investigation was to assess the validizy of utilizing the same semantic differential test as a measure of social evaluation for persons of different ages. The semantic differential -- a rating technique by which judgments of stimuli are made on seven-interval bipolar descriptive continua called "scales" -- came into being in the 1950's as a factor analytic technique to study meaning. Currently, the technique receives widespread usage as a measure of attitudes, including attitudes toward aging and the elderly.

However, a lack of stability across stimuli -- known as "concept-scale interaction" -- and a lack of stability across subjects -- known as "subject-scale interaction" -- have been found to occur with the semantic differential technique in various areas of research. Such instability may be caused by the relativity of the language learning experience; that is, for a given individual a symbol can acquire multiple meanings, and across individuals a symbol can acquire different sets of meanings. That instability might occur across stimulus persons and/or subjects of different ages is suggested by the existence of cross-age differences attributable to the biological aging process, the life cycle process, and the social change process. The possibility of instability poses two questions regarding the utilization of the semantic differential technique in the social evaluation of persons of different ages: "Can stimulus persons of different ages be compared?" and "Can subjects of different ages be compared?" In investigating these questions, 
the determining criterion is the generality of the resulting factor structures. 
METHODS: CONSTRUCTING AND TESTING A CROSS-AGE SEMANTIC DIFFERENTIAL

The general methods of the semantic differential technique consist of: 1) selection of scales, 2) selection of stimuli, 3) collection of data, and 4) analysis of the data by factor analysis. The study's application of these methods to the investigation of cross-age semantic stability in social evaluation is detailed below. In this report, the terms "younger adult" and "older adult" indicate persons aged 22 to 32 years and 60 years or older, respectively.

\section{SCALE SELECTION}

\section{Criteria for Selection}

Considerable attention was given to the selection of scales, for, as Osgood et al. (1957, p. 20) indicated, "The crux of the method, of course, lies in selecting the sample of descriptive polar terms." In describing the construction of new semantic differentials, Osgood et al. (1957, pp. 78-79) listed four criteria for selecting scales, the factorial composition of the scales, relevance of the scales to the stimulus being rated, semantic stability of the scales across stimuli and subjects, and linearity of the scales. 
Factorial Composition. Factorial composition of the scales refers to the problem of selecting scales so that all factors are represented. Usually, several standard reference scales for each of the previously isolated major factors -Evaluation, Potency, and Activity -- are included in a semantic differential. This procedure was followed in the current study. In addition to representing those factors already isolated, however, the ability to represent other factors should also be provided for in constructing a new semantic differential. This requirement is expressed by 0sgood et al. (1957, p. 79) thuslys

It is also true, of course, that the three dominant factors we have isolated do not exhaust the semantic space, and therefore dimensions highly significant for differentiating the concepts in a particular study might be lost entirely if one stuck to only evaluative, potency, and activity scales.

For this reason, scales in addition to the standard reference scales were selected from adjectives and short descriptive phrases suggested by a generating sample of younger adult and older adult subjects.

Relevance. The second criterion, relevance of the scales to the stimulus being rated, refers to whether the subjects can meaningfully differentiate the stimulus on the scales provided, or whether they will have to repeatedly check the neutral (or equal or irrelevant) position. Osgood et al. (1957, pp. 78-79) described this problem as follows:

For example, in judging a concept like ADLAI STEVENSON, one evaluative scale like beautiful-ugly may be comparatively irrelevant while another like fair-unfair may be 
highly relevant; on the other hand, just the reverse would be true for judging paintings. Since irrelevant concept-scale pairings usually yield neutral or "4" judgments, their inclusion reduces the amount of information gained with a given number of scales.

The inclusion of irrelevant scales was minimized by having the scales (other than the standard reference scales) be selected from adjectives and short descriptive phrases suggested by a generating sample as relevant to the task.

Semantic Stability. The third criterion, semantic stability of the scales across stimuli and subjects, refers to whether the scales have the same meaning across the range of stimuli and the range of subjects in a study. Osgood et al.(1957. p. 79) illustrated the stability-across-stimuli problem as follows:

Yet another criterion governing the selection of scales is their semantic stability for the concepts and subjects in a particular study. Whereas high-low can be expected to be stable across a set of sonar signals, it would not across a set of concepts which included both auditory and social concepts. Similarly, a scale like large-small is liable to strict denotative usage in judging physical objects like BOULDER and ANT, but is likely to be used connotatively in judging concepts like SIN and TRUMAN.

In the current study, the stability-across-stimuli problem was initially reduced by the utilization of a limited range of stimuli -- people. The stability-across-subjects problem was initially reduced by the utilization of a limited range of rating subjects -- healthy, active, college-educated individuals. In addition to this initial reduction of the semantic stability problem, further reduction can be expected through the utilization of the generated scales because of their relevance to 
both the stimulus models and subjects. Cross-age instability of the scales remaining within this limited stimulus and subject set constitutes the research problem of the current study, which was explained in detail in the first chapter of this report.

Linearity. 0sgood's final criterion, linearity, specifies that "scales should be linear between polar opposites and pass through the origin." Osgood et al. (1957, p. 79) described the problem thusly:

One example of nonlinearity we have discovered is that the scale rugged-delicate is not linear with respect to evaluation - both terms, when used separately, tend to be favorable in meaning, and hence this scale cannot both pass through the origin and be linear. At present we merely assume that the scale defined by familar and common opposites have these properties, but research on the problem needs to be done.

The current study, whenever possible, followed the procedure of using familiar and common opposites (e.g., good/bad), as defined by the generating subjects. When this was not possible, negatives rather than opposites were utilized (e.g., good/not good).

\section{Standard Reference Scales}

From Osgood et al., the following seven standard reference scales were selected for inclusion in the current study: good/ bad, nice/awful, beautiful/ugly, large/small, strong/weak, fast/ slow, and active/passive. The first three scales were selected to represent the Evaluation factor, the next two scales the Potency factor, and the last two scales the Activity factor. The scales were selected on the basis of their having large loadings on (or correlations with) the factor to be represented and small 
loadings on the other two factors (Osgood et al.,1957, p. 37). Generated Scales

Criteria For Selecting Scale-Generating Sample. Criteria for selecting individuals to participate included, age, sex, educational attainment, health, and activity level. Age ranges for the sample were set at 22 to 32 years of age for the younger adult subjects and 60 years or older for the older adult subjects. These two age ranges were chosen to provide a distinction between the age categories sufficient to allow any differences in attitudes to be revealed.

Considered of particular relevance to the study was the control of sex differences, social class differences, health differences, and activity level differences. Each age level of generating subjects contained equal numbers of males and females. Educational attainment was utilized as the indicator of social class; subjects were limited to college-educated individuals. The health of the generating subjects was standardized at the basic level that they were at least able to come to the campus to participate in the study. A high activity level on the part of the younger generating subjects was assumed because of their status as students; a comparably high activity level on the part of the older generating subjects was sought by focusing the soliciting for older subjects on various activity groups. Only one member of any married couple was included in the generating sample. 
Description of Scale-Generating Sample. Sixty subjects were selected to participate in the generation of scales -- 30 younger subjects and 30 older subjects. The average age of the younger generating subjects was 25 years (25 for both females and males); the average age of the older generating subjects was 68 years ( 69 for females, 67 for males). Each age level of generating subjects contained 15 males and 15 females. Educational attainment of the generating sample ranged from "some college" to the "Naster's degree" for the younger subjects, and from "some college" to the "Ph.D." for the older subjects. Both younger and older generating subjects came from a diversity of academic backgrounds, including business administration, education, liberal arts, science, and the social sciences. Of the older subjects, $83 \%$ indicated they were retired; the remainder described themselves as "semi-retired." In addition to being students, the younger generating subjects listed as occupations: business, child care, civil service, crafts, education, manual labor, medicine, secretarial, and writing. The older generating subjects listed as occupations, business, education, engineering, forestry, military, music, secretarial, social work, and writing. All of the younger generating subjects were native born; two of the older generating subjects indicated they were foreign born (Ireland and Canada) and one did not specify country of birth. At least 24 , or $80 \%$ of the younger generating subjects, and 27 . or $90 \%$ of the older generating subjects (one did not specify) had lived in the Portland SMSA for most of the last five years. 
Except for one older male, all generating subjects were Caucasian.

Scale-Generating Procedure. The generating subjects were individually scheduled at a time convenient to them to come to the Portland State University campus to participate in the study during the time period of Nay 23 through June 3, 1974. No reimbursements were offered to the generating subjects for their time and efforts; instead the generating subjects were informed that a report on the study findings would be made available to them as soon as the study was completed. Although 50 minutes had been stated as an estimate of time needed to accomplish the scale generating task, no time limit was imposed. Subjects took from 45 minutes to two hours to complete the nine-page scalegenerating questionnaire.

The first page of the questionnaire consisted of a letter to the subjects explaining the scale-generation aspect of the study:

To the Respondent:

The study you are being asked to participate in is part of an on-going research project at Portland State University. The purpose of this study is to acquire an understanding of the types of characteristics important in the social evaluation or perception of others.

This questionnaire is composed of two sections. The first section is concerned with the actual content matter of the study. The second section requests background information so that the results of the first section can be put into some perspective.

The first section may seem difficult to complete. However, your thoughtful and conscientious cooperation is necessary for the successful outcome of this study. I would like to thank you in advance for your assistance.

If you wish to make any comments regarding this questionnaire, please feel free to write them in the margins of the pages. However, in order that your responses be kept confidential, please do not sign your questionnaire. 
Five scale-generating requests were made of the subjects (Section one of the questionnaire). Each request was printed on a separate page of the questionnaire, and the subjects were instructed to: "Please do not look ahead. Finish each page of Section one before you turn to the next page."

The first two requests concerned the generation of scales relevant to the subjects' own age level. The subjects were asked:

Would you list 10 adjectives (or short phrases) that describe in a positive way the characteristics or attributes (personality, physical, or social) of a person of your sex and age? That is, list what you consider to be the good characteristics of a person of your sex. and age.

Then they were asked:

Would you list 10 adjectives (or short phrases) that describe in a negative way the characteristics or attributes (personality, physical, or social) of a person of your sex and age? That is, list what you consider to be the bad characteristics of a person of your sex and age.

The second two requests concerned the generation of scales relevant to the other age level. The younger generating subjects were asked:

Would you list 10 adjectives (or short phrases) that describe in a positive way the characteristics or attributes (personality. physical, or social) of a person of your sex and 60 years or more of age? You might wish to think of someone in particular, or even of a number of people, of that age and sex and list their good characteristics.

while the older generating subjects received the following request,

Would you list 10 adjectives (or short phrases) that describe in a positive way the characteristics or attributes (personality, physical, or social) of a person of your sex and 22 to 32 years of age? You might want to think of someone in particular, or even of a number of people, of that age and sex and list their good characteristics. 
Next the younger generating subjects were asked,

Would you list 10 adjectives (or short phrases) that describe in a negative way the characteristics or attributes (personality, physical, or social) of a person of your sex and 60 years or more of age? You might wish to think of someone in particular, or even of a number of people, of that age and sex and list their bad characteristics.

while the older generating subjects were asked:

Would you list 10 adjectives (or short phrases) that describe in a negative way the characteristics or attributes (personality, physical, or social) of a person of your sex and 22 to 32 years of age? You might wish to think of someone in particular, or even of a number of people, of that age and sex and list their bad characteristics.

The fifth and final scale-generating request, made of both age levels of subjects, was:

To help me define the adjectives as you use them, would you now go back and write the opposite of each characteristic you have written for each of the four lists you have made. For example, if you had listed "good" as a characteristic, you might list "bad" as its opposite.

Following completion of the scale-generating task, the subjects were requested (Section Two of the questionnaire) to provide information regarding: 1) educational background, 2) personal and occupational background, and 3) geographical background. Information obtained from section Two is summarized earlier in this report.

The questionnaire concluded with the request, "Please do not discuss this questionnaire with your colleagues for several weeks since they may be asked to take part in the study during that time."

Content Analysis and Selection of Scales. Of the 2400 possible responses (adjectives and short descriptive phrases) 
requested from the generating sample (60 subjects $\times 4$ stimuli $x 10$ responses), 2321 were received. The remaining 79 possible responses were left blank. Sixty of the 79 blanks were submitted by older generating subjects and 19 by younger generating subjects. Forty seven responses ${ }^{6}$ were listed in a direction contradictory to common usage -- e.g., "well groomed" was listed as a negative instead of a positive characteristic. Twenty-one of these reverse-direction responses were given by older subjects and 26 by younger subjects. The 47 reversedirection responses were deleted from consideration in subsequent tallies, thereby reducing the total number of responses to 2274. The 2274 usable responses were content analyzed by the author into scale classifications on the basis of 1) combining synonyms and 2) matching levels of abstraction.

The basic criterion for deciding whether two responses were synonyms or not was the common usage of the generating subjects. For example, if generating subjects commonly listed both of the two responses -- which might have been suspected by the author of being synonyms -- the two responses were then classified as being different. If, however, the common usage of the generating subjects was to list only one of the two responses, then the two responses were classified as being synonyms. In

6 These 47 reverse-direction responses were concerned with 14 of the subsequent 78 scale classifications, of which five were among those eventually selected for inclusion in the study's semantic differential (i.e.. amibitious, hardworking/lacking ambition, lazy, financially careful/financially careless, flexible/ inflexible, generous/selfish, and well groomed/poorly groomed.) 


\section{TABLE II}

\section{SCALES SUGGESTED BY GENERATING SUBJECTS}

Scales

considerate/inconsiderate

open minded/ closed minded

well groomed/poorly groomed

has desire to learn/has no desire to learn

loving/unloving

understanding/non-understanding

honest/dishonest

ambitious, hardworking/lacking ambition, lazy

flexible/inflexible

generous/selfish

healthy/unheal thy current events

enthusiastic/unenthusiastic

modest, humble/arrogant, know-it-all

has sense of humor/has no sense of humor

pleasant/unpleasant

friendly/unfriendly

sincere/insincere

independent/dependent

does physical exercise/does no physical exercise interesting to talk to/boring to talk to

careful of health/careless of health

alert/non-alert

intelligent/unintelligent

positive, optimistic/negative, pessimistic

responsible, reliable/irresponsible, unreliable

mature, understands self/immature, does not understand self

has good relations with people of other ages/ has poor relations with people of other ages patient, calm/impatient, agitated

non-bigoted/bigoted

involved in civic affairs/uninvolved in civic affairs

cooperative/uncooperative

happy/sad

non-complainer/complainer

has broad interests/has narrow interests

has respect for self/has disrespect for self

has good judgment/has poor judgment

good Iistener/poor Iistener 
TABLE II (CONTINUED)

Rank

39
40
41
42
43
44
45
46
47
48
49
50
51
52
53
54
55
56
57
58
59
60

61

62

63

65

66

67

68

69

70

71

72

73

75

76

77

Scales

extrovert, outgoing/introvert, withdrawn creative/uncreative

assertive/non-assertive

spiritually strong/spiritually lacking

perseveres/gives up

not overly critical of others/overly critical of others

socially engaged, socially active/socially disengaged, socially inactive open/closed

non-domineering, non-bossy/domineering, bossy future oriented/lives in past

appreciative of the arts/unappreciative of the arts experienced/inexperienced

financially careful/financially careless

energetic/lacking energy

organized/disorganized

poised, self confident/not poised, lacking self confidence

good looking/ugly

articulate/inarticulate

properly sexual/not properly sexual

non-worrier/worrier

competent/incompetent

has close family ties/ does not have close family ties

punctual/late

grateful/ungrateful

forgiving, accepting/unforgiving, non-accepting cultivates hobbies/does not cultivate hobbies trusting/mistrustrul

pleasant facial expression/unpleasant facial expression

spontaneous/not spontaneous

deep/shallow

appreciative of nature/unappreciative of nature decisive/uncertain

not overly materialistic/overly materialistic pleasant voice/unpleasant voice non-jealous/jealous

does not gossip/gossips

enjoys play/does not enjoy play

rich/poor

not nosy/nosy

young/old

* Scales are presented in the order of descending frequency; ties are not indicated. 
cases where the common-usage criterion was not sufficient to determine whether responses were synonyms or not, the decision was based on dictionary usage, thesaurus usage, or the investigator's usage of the response in question.

Differences in levels of abstraction of the responses were reconciled for the most part by the common-usage criterion also. For example, if common usage by the generating subjects was to utilize the response at a high level of abstraction (e.g.. "honesty"), then lower levels of abstraction (e.g.. "not lying," "not stealing," "not cheating") were combined into an "honesty" scale classification. Differences in levels of abstraction which were not directly reconcilable by the common-usage criterion because insufficient examplars existed were instead settled on the basis of the general level of abstraction for all responses. Content analysis of the responses resulted in 78 scale classifications (see Table II). Final phrasing for the scales which designate the scale classifications was determined on the basis of common usage, clarity, and brevity. Scales were selected from the 78 scale classifications for inclusion in the study's semantic differential by two different methods of tallying.

In the first method, the scales were tallied on the basis of the four elements of the responses, i.e., whether the scales were listed by an older or younger generating subject, by a male or female, about their own or the other age level, and whether as a positive or negative characteristic. This method 
of tallying was utilized in order to give equal weight to each of the response elements in the selection of scales. The basis for tallying was the number of subjects listing a particular scale per cell, and not the number of times a particular scale was listed per cell, thereby eliminating duplications within cells created by the content analysis. The four most frequent responses in each of the resulting 16 cells -- 26 different scales -- were selected for inclusion (see Table III).

In the second method of tallying, subtotals across cells were obtained on both the older and younger generating subjects' responses in order to ascertain which scales were most frequently used by each of the two age groups of generating subjects in describing people -- regardless of the stimulus person's sex or age, or the type of characteristic (i.e., positive or negative). The 15 most frequent responses for each of the age levels of generating subjects are presented in Table IV. All scales on this list not already included in the semantic differential being constructed were now selected for inclusion, bringing the total of generated scales to 30 .

\section{Young/01d}

In addition to the seven standard reference scales and the 30 scales suggested by the generating subjects, one other scale was included in the study's semantic differential. That scale -- young/old -- was included as a check on how old the stimulus models were perceived as being. The complete list of 38 scales selected for inclusion is presented in Table $\mathrm{V}$. 
TABLE III

MOST FREQUENT RESPONSES ACCORDING TO EQUAL WEIGHT TALLY SCHEME*

Generating Subjects

older

Male

Own Age

Other Age
Positive

Characteristics
Negative

Characteristics
Considerate

Heal thy

Alert

Involved in civic affairs

Ambitious, hardworking

Considerate

Involved in civic affairs

Responsible, reliable

Female

Own Age

Other Age
Unenthusiastic

Selfish

Unheal thy

Closed minded

Selfish

Lacking ambition, lazy

Closed minded

Inconsiderate

Poorly groomed Inconsiderate Unheal thy

Closed minded

Poorly groomed Inconsiderate Lacking ambition, lazy

Financially careless

Younger

Male

Own Age

Honest

Open minded

Intelligent

Considerate

Other Age

Open minded

Heal thy

Has sense of humor

Has desire to learn

Inconsiderate

Bigoted

Dishonest

Poorly groomed

Closed minded Uninformed about current events Complainer Arrogant, know1t-a11 
TABLE III (CONTINUED)

\begin{tabular}{|c|c|c|}
\hline $\begin{array}{l}\text { Generating } \\
\text { Subjects } \\
\end{array}$ & $\begin{array}{c}\text { Positive } \\
\text { Characteristics } \\
\end{array}$ & $\begin{array}{c}\text { Negative } \\
\text { Characteristics } \\
\end{array}$ \\
\hline \multicolumn{3}{|l|}{ Female } \\
\hline Own Age & $\begin{array}{l}\text { Intelligent } \\
\text { Has sense of humor } \\
\text { Friendly } \\
\text { Loving }\end{array}$ & $\begin{array}{l}\text { Unloving } \\
\text { Inconsiderate } \\
\text { Immature, does } \\
\text { not understand } \\
\text { self } \\
\text { Dishonest }\end{array}$ \\
\hline Other Age & $\begin{array}{l}\text { Loving } \\
\text { Understanding } \\
\text { Has desire to learn } \\
\text { Has sense of humor }\end{array}$ & $\begin{array}{l}\text { Closed minded } \\
\text { Not alert } \\
\text { Inflexible } \\
\text { Domineering, bossy }\end{array}$ \\
\hline \multicolumn{3}{|c|}{$\begin{array}{l}\text { * The top four scales per cell are presented in the order of } \\
\text { descending frequency; ties are not indicated. In order to save } \\
\text { space only the positive half of the scale is listed under posi- } \\
\text { tive characteristics and only the negative half under negative } \\
\text { characteristics. }\end{array}$} \\
\hline
\end{tabular}




\section{TABLE IV}

PIFTEEN MOST FREQUENT RESPONSES FOR OLDER AND YOUNGER GENERATING SUBJECTS*

\begin{tabular}{rll} 
Rank & $\begin{array}{l}\text { Older Generating } \\
\text { Subjects }\end{array}$ & $\begin{array}{l}\text { Younger Generating } \\
\text { Subjects }\end{array}$ \\
\cline { 2 - 3 } 1 & $\begin{array}{l}\text { Considerate } \\
\text { Well groomed }\end{array}$ & $\begin{array}{l}\text { Open minded } \\
\text { Considerate }\end{array}$ \\
3 & Ambitious, hardworking & Honest \\
4 & Has desire to learn & Loving \\
5 & Healthy & Understanding \\
6 & Open minded & Has sense of humor \\
7 & Generous & Flexible \\
8 & Loving & Has desire to learn \\
9 & Pleasant & Informed about current \\
10 & Understanding & events \\
11 & Cooperative & Non-bigoted \\
12 & Has good relations with & Well groomed \\
13 & people of other ages & Intelligent \\
14 & Does physical exercise & Mature, understands \\
15 & Alert & self \\
& Informed about current & Enthusiastic \\
& events &
\end{tabular}

* In order to save space, only the positive half of the scale is presented. 
TABLE V

\section{SCALES SELECTED FOR INCLUSION \\ IN SEMANTIC DIFFERENTIAL}

From Osgood et al.

Active/passive (A)

Beautiful/ugly ( $E$ )

Fast/slow (A)

Good/bad (E)

Iarge/small $(P)$

Nice/awful (E)

Strong/weak (P)

\section{From Generating Subjects}

Alert/non-alert

Ambitious, hardworking/lacking ambition, lazy

Considerate/inconsiderate

Cooperative/uncooperative

Does physical exercise/does no physical exercise

Enthusiastic/unenthusiastic

Financially careful/financially careless

Flexible/inflexible

Friendly/unfriendly

Generous/selfish

Has desire to learn/has no desire to learn

Has good relations with people of other ages/has poor relations with people of other ages

Has sense of humor/has no sense of humor

Heal thy/unheal thy

Honest/dishonest

Independent/dependent

Informed about current events/uninformed about current events Intelligent/unintelligent

Involved in civic affairs/uninvolved in civic affairs Loving/unloving

Mature, understands self/immature, does not understand self

Modest, humble/arrogant, know-it-all

Non-bigoted/bigoted

Non-complainer/complainer

Non-domineering, non-bossy/domineering, bossy

Open minded/closed minded

Pleasant/unpleasant

Responsible, reliable/irresponsible, unreliable

Understanding/non-understanding

Well groomed/poorly groomed

For Check on Perceived Ages of Stimulus Models

Young/old 


\section{STIMULUS SELECTION}

Selection of the stimuli for the present study involved a number of different decisions. These concerned the stimuli's age, type and mode of presentation, number and length of presentation, standardization, and presentation order.

\section{Age of Stimuli}

Age ranges chosen for the stimuli were set at 22 to 32 years for the younger stimuli and 60 years or older for the older stimuli. The same age ranges as were set for the scalegenerating subjects were chosen for the stimuli so that the suggested scales would be as relevant as possible to the stimuli.

\section{Stimulus Type and Mode of Presentation}

On the basis that responses to symbols are not generally isomorphic with responses to objects (0sgood, 1953), it was decided to utilize objects (i.e., stimulus models) instead of words as stimuli in the hopes of obtaining a more meaningful answer to the research question. That is, stimulus models were used in order to focus the study on attitudes toward people and not on attitudes towards words.

Next it had to be decided whether the stimulus models would be "live" or photographed people. For purposes of practicality and standardization, the mode of live stimulus models was eliminated as a viable mode of presentation. Moving photography was chosen because movements by a person communicate information which may be the basis for the formation of an attitude about that person. 
Whether to utilize actors or non-actors for the stimulus models had to be decided next. Non-actors were chosen on the basis that it was not acting performance which was pertinent to the study.

It was decided to utilize persons unknown to the subjects as stimulus models in order to standardize the portrayals across rating subjects who might otherwise vary in their knowledge of a "known" person. Because of their accessibility and their likelihood of being unknown to the rating subjects, it was decided to utilize for stimulus models videotaped portrayals selected from television documentaries taped by the Portland State University Television Services for their videotape library.

\section{Number of Stimuli and Length of Presentation}

Since it was desired to study responses toward both younger and older stimulus models (of both sexes), the minimum number of stimulus models would be four: one younger male, one younger female, one older male, and one older female. And, since no one individual could be expected to possess and/or exhibit all of the characteristics of the relevant age and sex group, the utilization of replicates would accrue the advantage of making the resulting data more general to an age and sex group instead of being specific to merely one individual. Consequently, it was decided to include one replication -- for a total of eight stimulus models. A one-minute stimulus model portrayal was chosen as providing an at least minimally adequate length for eliciting existing age attitudes (agreement with this opinion can be found 
in the television advertising arena, where advertisements even shorter in length than one minute are expected to create an image sufficient to sell a product).

Standardization of Stimuli

Effort was taken to standardize the eight stimulus models for all relevant variables (except age). In order to neutralize the effect of sex, the number of stimulus models of each sex in each age level was balanced. Standardization of situations was sought by using similar visual formats in presenting the stimulus models, and by deleting the sound tracks. All stimulus models were presented from a front view, sitting or standing still, talking to someone not on camera. By omitting the sound track, it was hoped to prevent the conversation topic from defining the situation.

All stimulus models were Caucasion. Ethnic origins and social class of the stimulus models were not ascertained.

\section{Presentation Order of Stimuli}

Due to limitations on resources, only one version of the stimulus model videotape was made. In ordering the stimulus models on the videotape, it was decided to place one member of each replicate pair in the first half of the taped presentation, and one member in the second half. This splitting of the appearances of the replicated stimulus models into two separate orderings was undertaken in order to reduce the effect -- caused by such factors as subject practice at rating, subject boredom, or subject exhaustion -- of the stimulus model's position on the 
tape. Which member of a replicate pair was placed in which half, and the order of the four stimulus models within each half, were randomly determined. As a result of this procedure, the following order of presentation was obtained: 1) older female, 2) younger female, 3) younger male, 4) older male, 5) older male, 6) younger male, 7) older female, and 8) younger female. Immediately prior to the appearance of each stimulus model on the videotape, a title -- PERSON1, PERSON 2, etc. -appeared on the tape for identification.

\section{DATA COLLECTION}

Data collection for the current study consisted of the rating of the eight videotaped stimulus models on the 38 scales by a volunteer rating sample of subjects.

\section{Criteria for Selecting Rating Sample}

In order to make the rating sample comparable with the generating sample, criteria utilized in soliciting individuals to participate as rating subjects were the same criteria utilized for the generating subjects, i.e., criteria concerning the individual's age, sex, educational attainment, health, and activity level. As with the generating subjects, the age range of the rating subjects was set at 22 to 32 years of age for the younger subjects and at 60 years of age or older for the older subjects. And, again, effort was taken to hold constant all relevant attributes of the rating subjects except for age. Consequently, within age levels, the rating sample was to be composed of equal numbers of males and females, so as to neutralize the 
effect of sex differences. The younger subjects were to be currently or recently enrolled college students; the older subjects were to be college educated, sufficiently heal thy to come to the campus to participate in the study, and solicited from various activity groups (the same groups as were utilized for the generating subjects). Only one member per married couple was invited to be in the rating sample, and there was no overlapping of subjects between the generating sample and the rating sample.

\section{Description of Rating Sample}

One hundred and twenty subjects were selected to participate in the rating of the stimulus models. Sixty of the rating subjects were older adults -- mean age of 69 years 7 (70 years for females, 68 years for males) -- and 60 were younger adults -- mean age of 26 years (for both males and females). $E_{a}$ ch level of rating subjects was composed of 30 males and 30 females. As with the generating sample, the educational level of the older rating subjects ${ }^{8}$ ranged from "some college" through the "Ph.D.." and that of the younger rating subjects from "some college" through the "Master's degree." And, like the generating sample, both age levels of rating subjects came from a variety of academic backgrounds. Of the 59 older rating subjects who

7 Three of the older female subjects did not specify age.

8 one older male rating subject indicated "special business courses"instead of college attendance. 
stated their retirement status, $71 \%$ indicated they were retired, 9 $10 \%$ indicated they were semi-retired, and $19 \%$ indicated they were not retired. For occupations, the older rating subjects indicated they were, or had been, involved in business, civil service, clerical work, education, engineering, finance, nousework, journalism, medicine, military, music, politics, research, and social work. In addition to being students, the younger rating subjects listed as occupations, business, cartography, clerical work, computer programming, domestic work, education, farming, medicine, and research. Five of the older rating subjects indicated they were foreign born (Austria, England, Germany -- two subjects, and South Africa); two of the younger rating subjects also indicated they were foreign born (both from Cenada). At least 54 , or $90 \%$ of the older rating subjects and 43 , or $72 \%$ of the younger rating subjects had lived in the Portland SMSA for most of the last five years. All 120 rating subjects were Caucasion.

\section{Rating Procedure}

As with the generating sample, the rating subjects were offered no reimbursement for their time and effort; they were instead informed that a report on the study findings would be made available to them as soon as the study was completed. Rating sessions for younger and older subjects were scheduled separately. The average number of rating subjects at a session was 3.4 for the older subjects and 6.2 for the younger subjects. Nineteen

$9_{\text {Three subjects counted in this category indicated they }}$ were not retired from housework, and one subject listed herself as "disabled." 
sessions were required to collect the data on the older subjects, 10 sessions were required for the younger subjects. For the younger subjects, the rating sessions occurred during the time period of November 12 to November 22, 1974; for the older subjects, the rating sessions occurred between November 13 and December 10, 1974.

The planned length of the data collection session was set at one hour, in order to keep the length within the subjects' level of willingness and ability to participate. One hour was estimated by the investigator to be an appropriate maximum length -- both from the point of view of the students in scheduling the rating session into their class schedules, and from the point of view of the more elderly subjects in not over-taxing limited energy levels. Within the projected one-hour rating session, time had to be allotted for 1) instructions and delays, 2) viewing of the stimulus models, 3) rating of the stimulus models, and 4) answering of the biographical questions. It was estimated that 20 minutes would be needed for instructions, delays, and biographical questions and 40 minutes for the viewing and rating of the stimulus models. Estimation procedures suggested by Osgood et al. (1957, p. 80) indicated that 40 minutes would be sufficient time to allow the subjects to rate the eight stimulus models on the 38 scales -- allotting one minute per videotape presentation and four minutes per rating.

In practice, no time limits were imposed on the rating sessions. Miost of the rating sessions took less than the 
estimated 60 minutes; some took a little longer. However, no subject had to leave a rating session before the session was completed. In order to see how accurate the Osgood et al. time-estimating procedure had been, rough measurements were made, whenever possible, on the amount of time required to complete the rating of a stimulus model. The amount of time needed by the younger subjects to rate a stimulus model ranged from, roughly, one to five minutes. In the average rating sesssion, the quickest younger subject used approximately 1.6 minutes to rate a stimulus model, and the slowest younger subject used approximately 2.7 minutes. The amount of time needed by the older subjects to rate a stimulus model ranged from, roughly, one to eight minutes. In the average rating session, the quickest older subject finished a rating in approximately 2.3 minutes, and the slowest older subject in approximately 3.6 minutes. For the average rating session, then, the time estimates of four minutes per stimulus model appear to have been approximately one minute too long for the younger rating subjects and just about correct for the older subjects. In general, the earlier stimulus models required more time to rate than the later stimulus models.

Ratings by all subjects were performed in the same room. A television monitor screen was placed at one end of the rating room, faced by seating for 10 people. The monitor was elevated on a stand so that it would not be obscured from view by another rating subject. The room was brightly lighted with ceiling lights, except for the end directly over the monitor. Upon entering the room, the rating subjects were greeted by the 
investigator and invited to take whichever seat before the monitor they preferred. Coffee was offered, and pencils and test booklets were passed out to the rating subjects.

The 20-page test booklets were composed of two pages of instructions, two pages of scales for each stimulus model, and two pages of biographical questions. In order to assist the rating subjects to link the rating sheets with the correct stimulus model, the first page of scales for a particular stimulus model was labeled "PERSON 1," "PERSON 2," etc., while the second page was labeled "Continuation of PERSON 1," "Continuation of PERSON 2," etc. Three different versions of the test booklets were utilized in order to reduce the effect of position of the scales. In addition, the direction -- negative to positive or positive to negative -- of the scales was randomly varied on each of the three versions.

To begin the rating session, the investigator read aloud the instructions printed at the beginning of the test booklet while the subjects read along on their own copies. The instructions were as follows:

The purpose of this study is to measure the types of characteristics important in the perception of others. You are requested to rate your perceptions of eight people on a series of descriptive scales (for example. on the scale: good bad).

Each person to be evaluated will appear visually -but without sound -- on the videotape monitor for approximately one minute. You may sometimes feel you have not received sufficient information about the person to really evaluate that person. However, please generalize or guess from the clues that are present in the videotape presentation. [ The investigator interrrupted the instructions here to point out that the subjects were being requested to indicate a first impression only. and that they would in no way be held to that rating for any final judgment about the stimulus model]. 
Following each one-minute appearance on the videotape monitor, four minutes will be allowed for you to rate your perceptions of the person. At the conclusion of the four-minute rating period, a new person will appear on the videotape monitor and the rating process will start over again. This format will be followed until all eight people are evaluated. For each person to be evaluated a set of 38 scales is provided on which to rate your perceptions. You are to rate your perceptions of the person on each of these scales in order. Here is how the scales are to be interpreted:

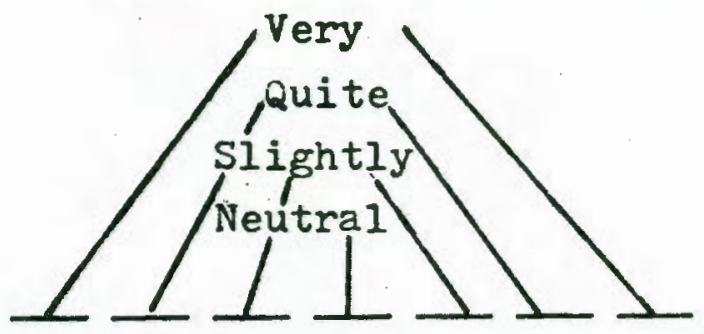

IMPORTANT: (1) Place your check-marks in the middle of spaces, not on the boundaries:

(2)

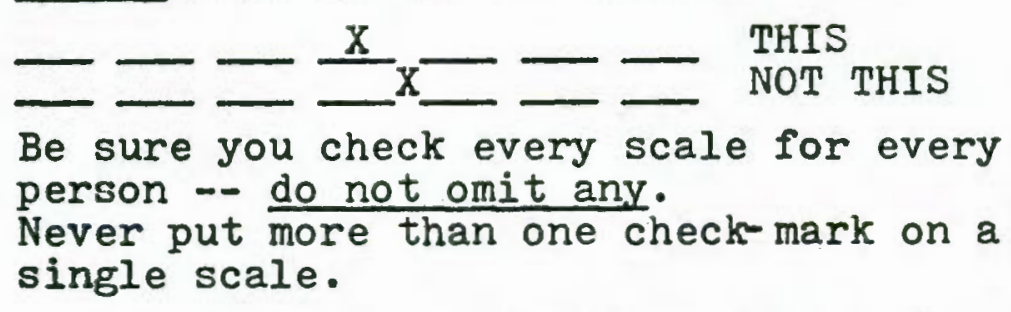

For each scale make a separate and independent judgment. Work at fairly high speed through this test. Do not worry or puzzle over individual scales. It is your first impressions, the immediate "feelings" about the people being evaluated that we want. On the other hand, please do not be careless, because we want your true impressions.

Please do not talk during the test.

After the reading of the instructions, the investigator made the following statement,

Will you now flip through your questionnaire and see if you have all the pages. It should go: PERSON 1 , Continuation of PERSON 1, PERSON 2, Continuation of PERSON 2, and so on through PERSON 8. Then there should be two pages of questions about you. Is anybody's questionnaire missing pages or out of order?

Do you have any questions about what you are to do?

Let"s begin. PERSON 1 will now appear for one minute on the monitor. Will you please observe PERSON 1 closely. 
The subjects were asked to leaf through their test booklets as much to orient themselves to the dimensions of the rating task as to locate any missing or mis-ordered pages. Immediately following the one-minute videotape presentation of a stimulus model, the investigator requested the subjects to indicate their first impressions of the stimulus model on their rating sheets. As soon as all subjects appeared to be finished rating a stimulus model, the investigator asked if anyone wanted more time for that rating; if no one requested more time, the next stimulus model was presented on the videotape monitor.

After completing the ratings of all eight stimulus models, the subjects were requested to provide information regarding their: 1) educational background, 2) personal and occupational background, and 3) geographical background. The test booklet gave the following explanation for asking the biographical questions:

Would you please provide information on your background (educational, personal and occupational, and geographical) as requested below. For the most part, this background information is not itself part of the study, but it is important in order to describe the sample of respondents who took part in the study and, consequently, to describe the population to which the study findings may be generalized.

In order that your responses be kept confidential, please do not sign your questionnaire.

Information received in this section of the test booklet was summarized earlier in this report.

All rating subjects were requested orally by the investigator to not discuss the study for several weeks with"anyone 
who wasn't here with you," and in writing by the test booklet to: "Please do not discuss this study with your colleagues for several weeks since they may be asked to take part in the study during that time."

IV. DATA ANALYSIS

\section{Data Preparation}

Scores were assigned to the ratings by coding each scale as follows:

negative pole 1234261 positive pole The scale young/old was coded with young as the positive pole and old as the negative pole. This assignment. of polarity was arbitrary - - it was not empirically derived as was the polarity of the generated scales -- and thus, in inspecting the study results in the next chapter, no significance should be attached to the polarity of the scale young/old per se. Following coding, the scores were keypunched onto computer cards and the three test booklet versions were reformatted into one version by an IBM 519 Reproducing Punch.

of the 36,480 pieces of social evaluation information requested from the rating subjects (eight stimulus models $X$ 38 scales $X 120$ subjects), 64 were left blank. Sixty-two of these missing values were contributed by older rating subjects and two by younger rating subjects. Of the stimulus models, PERSON 1 received the most missing values (35), while PERSONS 2 through 8 received from two to seven missing values each. Missing values occurred on 30 of the 38 scales, with the largest number -- eight -- occurring on the scale good/bad (five from 
one subject alone). From one to four missing values occurred on each of the other 29 scales. The coefficients of correlation of each scale with every other scale were calcalated using the BNiD03D "Correlation with Item Deletion" program to delete the 64 missing values.

\section{Factor Analysis}

Answers were then sought to three questions: How many factors are there underlying the scales? What scales are associated with what factors? How strongly are the scales associated with the factors? To answer these questions, the correlation matrix was factor analyzed using the BNiD08M "Factor Analysis" program (see Harman, 1960, for a discussion of the factor analytic technique). A principal axis solution was performed (i.e., the diagonal elements of the correlation matrix were unaltered and, thus, the initial communality estimates equaled 1.0). A maximum of five iterations was specified for the communalities, and the number of factors to be extracted was limited to factors with eigenvalues ${ }^{10}$ greater than 1.0 . The resulting unrotated factor matrix, al though it accounted for a certain percentage of the common factor variance of the scales, did not, however, provide a meaningful factor structure, since the placement of the reference axes was determined by a principal axis solution. In order to achieve a more meaningful structure, that is, to locate the primary attitudinal dimensions underlying the scales, the axes were rotated

${ }^{10} \mathrm{An}$ eigenvalue, which is the root of the characteristic equation $[R-\lambda I]=0$ used to solve for the unrotated factors, is equal to the sum of the squared loadings on a factor. 
according to Thurstone's principles of simple structure. As is common practice in semantic differential studies, the factors were rotated orthogonally; that is, right angles were maintained between the axes and thus the factors were kept independent. A varimax criterion of rotation of the factors was employed -with a maximum of 50 iterations specified -- using Kaiser normalization (Kaiser, 1958).

In order to investigate the semantic stability of the scales across the age levels of stimulus models and subjects, four separate factor analyses of the scales were performed. Following Heise's (1969, p. 416) advice that: "if one wants to study concept-scale interactions, one should carry out all analyses and comparisons within a single subject population," the scales were factor analyzed separately for the younger subjects and the older subjects. Using parallel logic, it was decided to investigate subject-scale interaction by performing separate factor analyses of the scales for the younger stimulus models and the older stimulus models. Thus, four separate factor analyses of the scales were performed (see Table VI): younger stimulus models/younger subjects (YY), younger stimulus models/ older subjects (YO), older stimulus models/older subjects (00), and older stimulus models/younger subjects (OY). Since each subject was entered as four observations in each of the two age appropriate factor analyses -- once for each stimulus model rated -the number of observations per analysis equaled 240 . 
TABIE VI

DESIGN OF SEPARATE FACTOR ANAIYSES

Subjects

\begin{tabular}{ccc} 
Stimulus Models & Younger & Older \\
\cline { 2 - 3 } Younger & $Y Y$ & YO \\
Older & OY & 00
\end{tabular}

\section{v. IIMITATIONS OF THE STUDY}

Generalizability of the study results may be limited by certain unavoidable shortcomings of the research design regarding size, scope, standardization, ability to elicit attitudes, and data handling. Thus, the findings of this study are of an exploratory rather than of a definitive nature.

\section{Size}

The number of stimulus models, the number of generating subjects, the number of rating subjects, and the number of scales are all small $(n=8,60,120$, and 38 , respectively). They may, therefore, lack representativeness. Furthermore, the study was undertaken with only one version of the adjective generating questionnaire, one version of the stimulus model videotape, and three versions of the semantic differential test. As a consequence, the study findings might be biased by position effect. 


\section{Scope}

The scope of the design, which was limited to two age levels of adults and to certain types of subjects, poses further questions about the findings' representativeness. The extent to which younger and older adults are representative of the entire adult age span remains unknown. Perhaps, as some gerontologists have suggested, younger and older adults are more similar to each other than they are to middle-aged adults -- either because of cohort differences or because of life stage differences. In addition, the subjects were required to be college educated, healthy, and active; only one of the subjects was non-Caucasian. The generalizability of findings based on such a sample also remains unknown.

\section{Standardization}

Standardization deficiencies -- occurring in the stimulus models, the subjects, or the study setting -- may also tend to limit the generalizability of the study results. Because of the difficulty in finding television portrayals of the desired types of people appearing alone in a standardized format for at least one minute, the standardization of the stimulus models was not as complete as might have been desired. Also, those rating subjects who could lip read would have been able to acquire a different perception of the stimulus models than those who could not lip read. In addition, since no example stimulus model on which to practice rating was provided for the subjects, ratings of PERSON 1 had to serve for both practice and 
data (note the relatively large number of missing values on PERSON 1).

Likewise, standardization of the subjects (for all relevant attributes except age) might have been less than desired. For example, the age range for the older subjects was longer than that for the younger subjects ( 30 years vs. 11 years); consequently, there was more of a likelihood of multiple age cohorts being included in the older sample than in the younger sample. Also, only educational attainment was utilized in standardizing social class -- occupation and income were not required to be comparable.

Standardization deficiencies might also have occurred in the setting of the study. For example, the campus setting might have been less familiar and therefore more distracting to the older subjects than to the younger subjects. And, because the subjects were not all scheduled to participate in the study at the same time, differences might have existed in the subjects' prior knowledge of the study tasks, in the investigator's handling of the testing sessions, in the exigencies of external events, and in the agreeableness of the weather.

\section{Ability to Elicit Attitudes}

Of particular concern here are the age focus of the study, the length of stimulus model presentations, and the study's volunteer subjects. The age focus of the study was perhaps too clear to both groups of subjects -- generating and rating. Some subjects expressed a reluctance to describe or rate younger 
and older persons differently. This problem was complicated by a reluctance on the part of some of the rating subjects to commit themselves to an evaluation of a person based on a one-minute observation. And the type of individual who consents to act as a volunteer in a research project -- under no constraint of reward or punishment -- might well be the type of individual who tends to be charitable in describing and rating others (i.e., "good sayers").

\section{Data Handling}

Certain aspects of how the data was handled during the scale generating and stimulus model rating stages of the study might also tend to limit the generalizability of the study findings. For example, during the classification and tallying of the generated scales, the decisions regarding synonyms and levels of abstraction were admittedly arbitrary to the investigator and not subjected to any reliability measures. And, of course, the current study is subject to all of the limitations general to semantic differential analyses.

\section{SUMMARY}

Eight videotaped stimulus models were rated by 120 subjects, using a semantic differential composed of 38 scales. Seven of the scales were selected as standard reference scales from previous studies, 30 were suggested by a volunteer generating sample of 30 younger and 30 older subjects (balanced in number for sex and selected to be as comparable as possible except for age) as relevant for describing younger and older 
individuals, and one was included as a check on the perceived ages of the stimulus models.

The stimulus models consisted of four younger and four older adults; each age level of stimulus models contained two males and two females. The eight stimulus models were nonactors, unknown to the rating subjects, and presented for one minute in a standardized visual format and without sound. AII stimulus models were Caucasian.

The volunteer rating sample of 120 subjects was composed of 60 younger and 60 older subjects, with each age level of rating subjects containing 30 females and 30 males. There was no overlapping of subjects between the generating and rating samples, and only one member per married couple was included in a given sample. All subjects but one were Caucasian. The resulting scale scores were factor analyzed to ascertain whether they remained stable across stimulus model and subject age levels. Analysis was made with the BMD08M "Factor Analysis" program, using as input the correlation matrix computed by the BMDO3D "Correlation with Item Deletion" program (utilized to delete missing scale values). Four separate factor analyses of the scales were performed -- younger stimulus models/younger subjects, younger stimulus models/older subjects, older stimulus models/older subjects, and older stimulus models/ younger subjects -- permitting comparisons between the factor matrices for concept-scale and subject-scale interaction. The factor analyses consisted of principal axis solutions with varimax rotation of the factors. 
Possible limitations on the generalizability of the study findings are posed by research design considerations of size, scope, standardization, ability to elicit attitudes, and data handling procedures. 


\section{CHAPTER III}

\section{RESULTS: STABILITY AND INSTABILITY OF A CROSS-AGE SEMANTIC DIFFERENTIAL}

The results of the four separate factor analyses of the scales -- younger stimulus models/younger subjects (YY), younger stimulus models/older subjects(YO), older stimulus models/older subjects $(00)$, and older stimulus models/younger subjects (OY) -provide comparative evidence bearing on the cross-age stability of the semantic differential technique in the measurement of social evaluation. Findings regarding the question of crossage semantic stability are considered from both of the opposing foci of stability and instability. First, the stability aspect is examined: to what degree are the factors from the two different age levels the same? Second, the opposite focus, instability, is emphasized, on which factors or scales do major differences between the two age levels occur? Following the discussions of stability and instability, the findings regarding the scale young/old are considered.

\section{FACTOR MATRICES}

The rotated factor matrices for the four factor analyses are presented in Tables VII - X. The column entries, which are called "loadings" and are interpreted like correlation coefficients (i.e., the loadings range from -1.0 to +1.0 ), indicate 
the degree and direction of the association of the scales with the factors. For example, in Table VII, the loading of the scale pleasant/unpleasant on Factor $A$ is .82 , and the association between the attribute "pleasant" and Factor $A$ is positive. The percent of the variance of a scale shared with a factor is equal to the squared factor loading multiplied by 100; for example, the percent of the variance of pleasant/unpleasant held in common with Factor $A$ is equal to $\left(.82^{2}\right)(100)$ or $67 \%$. The common factor variance of a scale, its communality, is given in the column headed " $h^{2}$ ". The communality of a scale equals the sum of its squared factor loadings; for example, the communality of pleasant/unpleasant is equal to $\left(.82^{2}\right)+\left(.21^{2}\right)+\left(.06^{2}\right)$, or .73. This means that $73 \%$ of the variance of the scale pleasant/ unpleasant has been accounted for by the three factors, leaving $27 \%$ of the variance unaccounted for by the common factors. The order of presentation of the scales in each of the four tables was determined individually for each of the factor matrices by the magnitude of the scale loadings on the factors. Scales with their largest loadings on Factor A are presented first, followed by scales with their largest loadings on Factors $B$ and C, respectively. In this report, scales considered to be involved in a factor are those which have $25 \%$ or more of their variance in common with that factor (i.e., absolute loadings of . 50 or greater).

Three factors were defined by each of the four factor analyses; the composition of these factors is discussed in detail 
in the next section of this chapter. The variance -- total and common -- accounted for by each of the four factor analyses is compared in Table XI. The percent of total variance in the scales accounted for by the four factor analyses -- i.e., the amount of common variance -- ranged from $49 \%$ to $55 \%$, with the least variance being accounted for for the younger stimulus models/younger subjects and the most for the older stimulus models/older subjects. From the opposite perspective, then, from $45 \%$ to $51 \%$ of the total variance is not common variance; it can be attributed to error or to the specificity of the scales. Factor A accounts for the largest percentage of the total variance (25\% to $31 \%$ ) for each factor analysis, Factor B for the next largest percentage ( $16 \%$ to $21 \%$ ), and Factor $\mathrm{C}$ for the smallest percentage ( $3 \%$ to $8 \%$ ). As can be seen, Factor C is a very weakly defined factor, with Factors $A$ and $B$ jointly accounting for from $84 \%$ (OY) to $94 \%$ ( $Y O$ ) of the common variance. Findings relevant to this study consist of evidence regarding the stability of the three factors across the two stimulus model age levels and across the two subject age levels. Cross-age comparisons of factors within subject age levels comprise evidence regarding the stability of the factors across stimulus model age levels. Likewise, cross-age comparisons of factors within stimulus model age levels comprise evidence regarding the stability of the factors across subject age levels. 


\section{TABLE VII}

ROTATED FACTOR MATRIX, YOUNGER
STIMULUS MODELS/YOUNGER SUBJECTS *

Scales

Pleasant

Understanding

Generous

Considerate

Nice

Cooperative

Loving

Flexible

Friendly

Has good relations with

people of other ages

Good

Non-bigoted

Non-domineering, non-bossy

Modest, humble

Open minded

has sense of humor

Honest

Non-complainer

Mature, understands self

Well groomed

Active

Strong

Fast

Intelligent

Alert

Enthusiastic

Independent

Informed about current events

Involved in civic affairs

Ambitious, hardworking

Iarge

Heal thy

Does physical exercise

Has desire to learn

Beautiful

Young

Financially careful

Responsible, reliable
Factors

\begin{tabular}{cccc}
\multicolumn{3}{c}{ Factors } & \multicolumn{1}{c}{${ }^{2}$} \\
\cline { 1 - 2 } $\mathrm{A}$ & $\mathrm{B}$ & $\mathrm{C}$ & \\
\cline { 1 - 2 }$(.82)$ & .21 & .06 & .73 \\
$(.81)$ & .04 & .18 & .70 \\
$(.80)$ & -.04 & .16 & .66 \\
$(.79)$ & -.02 & .26 & .69 \\
$(.78)$ & .17 & .01 & .64 \\
$(.77)$ & .03 & .18 & .63 \\
$(.76)$ & .07 & .01 & .59 \\
$(.76)$ & -.01 & .19 & .61 \\
$(.73)$ & .19 & -.07 & .57
\end{tabular}

$\left(\begin{array}{llll}.70 & -.01 & .17 & .52\end{array}\right.$

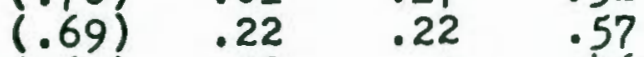

$\begin{array}{llll}(.67) & .08 & .10 & .46\end{array}$

$\begin{array}{llll}(.66) & -.44 & .111 & .65\end{array}$

$\begin{array}{llll}(.66) & -.49 & .18 & .71\end{array}$

$\begin{array}{llll}(.65) & .16 & .25 & .52\end{array}$

$\begin{array}{llll}(.62) & .19 & -.08 & .42\end{array}$

$\begin{array}{llll}(.55) & .17 & .32 & .44\end{array}$

$\begin{array}{llll}(.53) & .14 & .16 & .33\end{array}$

$\begin{array}{llll}.48 & .35 & .45 & .55\end{array}$

$\begin{array}{llll}.41 & .29 & -.03 & .25\end{array}$

$\begin{array}{llll}.00 & (.73) \quad .10 \quad .55\end{array}$

$\begin{array}{llll}-.06 & (.71) & .03 & .030\end{array}$

$\begin{array}{rrrr}-.04 & (.65) \quad .06 & .043\end{array}$

$\begin{array}{llll}.27 & (.65) & .37 & .63\end{array}$

$\begin{array}{llll}.21 & (.63) & .14 & .46\end{array}$

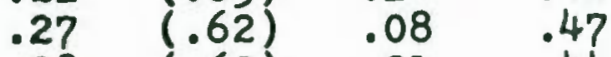

$\begin{array}{llll}-.08 & (.62) & .21 & .44\end{array}$

$\begin{array}{llll}.08 & (.55) & .07 & .32\end{array}$

$\begin{array}{llll}.01 & (.55) & .01 & .31\end{array}$

$\begin{array}{llll}.14 & (.55) & .24 & .38\end{array}$

$\begin{array}{llll}-.17 & (.53) & -.17 & .174\end{array}$

$\begin{array}{llll}.28 & (.52) & -.02 & .35\end{array}$

$\begin{array}{llll}.09 & (.50) & -.20 & .30\end{array}$

$\begin{array}{llll}.27 & .46 & .35 & .41\end{array}$

$\begin{array}{llll}.42 & .44 & -.17 & .40\end{array}$

$\begin{array}{llll}.15 & .28 & -.06 & .061\end{array}$

$\begin{array}{llll}.24 & -.01 & (.59) & .40\end{array}$

$\begin{array}{llll}.42 & .16 & (.57) \quad(.53)\end{array}$

* Varimax rotation. In order to save space, only the positive half of the scale is listed. Factor loadings greater than or equal to $|.50|$ are indicated in parentheses. $N=240$. 
ROTATED FACTOR MATRIX, YOUNGER

STIMULUS MODELS/OLDER SUBJECTS*

$\underline{\text { Scales }}$

Cooperative

open minded

Pieasant

Considerate

Flexible

niodest, numble

Generous

Nice

Has good relations with

people of other ages

Loving

Non-complainer

Non-domineering, non-bossy

Good

Friendly

Non-bigoted

Understanding

Well groomed

Has sense of humor

Honest

Responsible, reliable

Beautiful

Financially careful

Has desire to learn

Iarge

Alert

Active

Strong

Enthusiastic

Ambitious, hardworking

Fast

Independent

Does physical exercise

Mature, understands self

Heal thy

Involved in civic affairs

Intelligent

Informed about current events Young

\begin{tabular}{|c|c|c|c|}
\hline \multicolumn{3}{|c|}{ Factors } & $h^{2}$ \\
\hline A & B & C & \\
\hline $\begin{array}{l}(.82) \\
(.80) \\
(.80) \\
(.80) \\
(.79) \\
(.78) \\
(.78) \\
(.77)\end{array}$ & $\begin{array}{r}.18 \\
.08 \\
.24 \\
.10 \\
.00 \\
-.25 \\
.14 \\
.22\end{array}$ & $\begin{array}{r}.11 \\
.05 \\
-.10 \\
.26 \\
.02 \\
.04 \\
.14 \\
.06\end{array}$ & $\begin{array}{l}.71 \\
.65 \\
.71 \\
.71 \\
.63 \\
.68 \\
.64 \\
.65\end{array}$ \\
\hline $\begin{array}{l}(.77) \\
(.75) \\
(.73) \\
(.72) \\
(.72) \\
.70) \\
(.69) \\
(.67) \\
(.60) \\
(.60) \\
(.58) \\
(.58) \\
(.53) \\
.47 \\
.42 \\
. .31 \\
.07 \\
.03 \\
.04 \\
.28 \\
.23 \\
.06 \\
-.03 \\
.06 \\
.38 \\
.29 \\
.09 \\
.15 \\
.02 \\
.00\end{array}$ & $\begin{array}{r}.18 \\
.14 \\
.11 \\
-.24 \\
.30 \\
.28 \\
-.03 \\
.21 \\
.30 \\
.28 \\
.30 \\
.33 \\
.28 \\
.19 \\
.39 \\
.24 \\
(.77) \\
(.76) \\
(.75) \\
(.70) \\
(.68) \\
(.63) \\
(.57) \\
(.52) \\
(.50) \\
.48 \\
.44 \\
.43 \\
.35 \\
.18\end{array}$ & $\begin{array}{r}.18 \\
.11 \\
-.06 \\
-.01 \\
.18 \\
-.24 \\
-.06 \\
.15 \\
.02 \\
-.28 \\
.29 \\
.46 \\
-.13 \\
.37 \\
.03 \\
.08 \\
-.07 \\
.00 \\
.17 \\
-.09 \\
.32 \\
-.07 \\
.15 \\
-.07 \\
.31 \\
.03 \\
-.06 \\
-.05 \\
-.01 \\
-.026\end{array}$ & $\begin{array}{l}.65 \\
.60 \\
.55 \\
.58 \\
.64 \\
.62 \\
.48 \\
.51 \\
.46 \\
.52 \\
.52 \\
.65 \\
.38 \\
.39 \\
.33 \\
.16 \\
.61 \\
.58 \\
.59 \\
.58 \\
.61 \\
.41 \\
.35 \\
.28 \\
.49 \\
.31 \\
.20 \\
.21 \\
.12 \\
.10\end{array}$ \\
\hline
\end{tabular}

*Varimax rotation. In order to save space, only the positive half of the scale is listed. Factor loadings greater than or equal to 1.501 are indicated by parentheses. $N=240$. 
TABLE IX

ROTATED FACTOR MATRIX, OLDER

STIMULUS MODELS/OLDER SUBJECTS*

\section{Scales}

Cooperative

Open minded

Generous

Und ers tanding

Nice

Considerate

Pleasant

Flexible

Has good relations with

people of other ages

Non-bigoted

Loving

Friendly

Nodest, humble

Non-complainer

Good

Has sense of humor

Beautiful

Active

Strong

Independent

Fast

Involved in civic affairs

Enthusiastic

Alert

Ambitious, hardworking

Informed about current events

Heal thy

Non-domineering, non-bossy

Has desire to learn

Does physical exercise

Intelligent

Mature, understands self

Well groomed

Large

Honest

Financially careful

Responsible, reliable

Young

\begin{tabular}{|c|c|c|c|}
\hline \multicolumn{3}{|c|}{ Factors } & $h$ \\
\hline A & $B$ & C & \\
\hline $\begin{array}{l}.80) \\
.80 \\
.78) \\
.78) \\
.77) \\
.76) \\
.75) \\
.75)\end{array}$ & $\begin{array}{r}-.01 \\
.16 \\
.10 \\
.16 \\
.11 \\
-.02 \\
.08 \\
.05\end{array}$ & $\begin{array}{r}-.01 \\
-.02 \\
.07 \\
.09 \\
.24 \\
.17 \\
.17 \\
-.15\end{array}$ & $\begin{array}{l}.64 \\
.66 \\
.63 \\
.64 \\
.66 \\
.61 \\
.60 \\
.59\end{array}$ \\
\hline $\begin{array}{l}(.75) \\
(.74) \\
(.73) \\
(.71) \\
(.69) \\
(.69) \\
(.59) \\
(.58) \\
(.57) \\
. .06 \\
.06 \\
-.08 \\
.04 \\
.17 \\
.12 \\
.18 \\
.14 \\
.17 \\
.26 \\
(.55) \\
(.53) \\
.12 \\
.30 \\
.41 \\
.36 \\
-.10 \\
.31 \\
.04 \\
.42 \\
.13\end{array}$ & $\begin{array}{c}.27 \\
-.08 \\
.13 \\
.14 \\
(-.50) \\
.12 \\
.18 \\
.27 \\
.26 \\
(.86) \\
(.83) \\
(.73) \\
(.73) \\
(.73) \\
(.72) \\
(.70) \\
(.68) \\
(.67) \\
(.65) \\
(-.58) \\
(.54) \\
(.51) \\
(.50) \\
.43 \\
.39 \\
.37 \\
.03 \\
.46 \\
.40 \\
.22\end{array}$ & $\begin{array}{r}-.01 \\
-.06 \\
.34 \\
.28 \\
.02 \\
.04 \\
.45 \\
-.03 \\
.16 \\
.02 \\
.14 \\
.11 \\
-.05 \\
-.03 \\
.05 \\
.16 \\
.37 \\
.03 \\
.26 \\
-.17 \\
.04 \\
-.15 \\
.30 \\
.28 \\
.31 \\
.34 \\
(.66) \\
(.57) \\
(.57) \\
-.29\end{array}$ & $\begin{array}{l}.63 \\
.55 \\
.66 \\
.60 \\
.73 \\
.49 \\
.58 \\
.41 \\
.41 \\
.74 \\
.71 \\
.56 \\
.53 \\
.56 \\
.53 \\
.54 \\
.61 \\
.48 \\
.56 \\
.67 \\
.57 \\
.29 \\
.43 \\
.43 \\
.37 \\
.26 \\
.53 \\
.53 \\
.65 \\
.15\end{array}$ \\
\hline
\end{tabular}

* Varimax rotation. In order to save space, only the positive half of the scale is listed. Factor loadings greater than or equal to 1.501 are indicated by parentheses. $N=240$. 


\section{TABLE X}

ROTATED FACTOR MATRIX, OLDER STIMULUS MODELS/YOUNGER SUBJECTS *

Scales

Pleasant

Flexible

Open minded

Cooperative

Considerate

Understanding

Nice

Miodest, humble

Friendly

Has good relations with

people of other ages

Generous

Loving

Beautíful

Good

Non-complainer

Non-domineering, non-bossy

Has sense of humor

Non-bigoted

Mature, understands self

Has desire to learn

Active

Strong

Independent

Enthusiastic

Fast

Ambitious, hardworking

Heal thy

Alert

Involved in civic affairs

Intelligent

Informed about current events

Does physical exercise

Iarge

Responsible, reliable

Honest

Financially careful

Well groomed

Young

\begin{tabular}{cc}
\multicolumn{3}{c}{ Factors } \\
\hline A & B \\
\hline
\end{tabular}

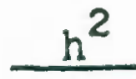

$\begin{array}{rrrr}(.81) & .09 & .34 & .78 \\ (.77) & .17 & -.15 & .65 \\ (.77) & .20 & -.11 & .64 \\ (.75) & .01 & .17 & .60 \\ (.73) & .02 & .27 & .60 \\ (.72) & .09 & .22 & .58 \\ (.70) & -.04 & .46 & .69 \\ (.68) & -.41 & .17 & .66 \\ (.68) & .15 & .35 & .60\end{array}$

(.67) $.23 \quad .08$

$(.66)-.01 \quad .36$

$(.65) \quad .03 \quad .43$

$(.63) \quad .24$

(.61) .10

.17

(.51)

$(.59) .16$

.05

$(.57)(-.52)-.07$

$\begin{array}{ll}(.57) \quad .31 & .19\end{array}$

$(.56) \quad .17 \quad-.17$

$\begin{array}{lll}(.54) & .29 & .23\end{array}$

$\begin{array}{lll}(.53) \quad .42 & .16\end{array}$

$-.04$

$(.79)$

.00

$-.08$

.09

$(.75)$

.13

$(.73)-.02$

$\begin{array}{ll}.16 & (.72) \quad .14\end{array}$

$.00 \quad(.67)-.19$

$.23 \quad(.64) \quad .34$

$.23 \quad(.59) \quad .19$

$.20 .(.58) \quad .18$

$.04 \quad(.53) \quad .06$

$.44 \quad(.52) \quad .17$

$\begin{array}{lll}.30 & (.51) & .03\end{array}$

$\begin{array}{lll}.19 & .44 & .00\end{array}$

$\begin{array}{lll}.03 & .26 \quad .14\end{array}$

$\begin{array}{lll}.18 & .47 & (.60)\end{array}$

$.44 \quad .16$

$.12 \quad .25$

$.27 \quad .35$

$(.58)$

(. 51$)$

.36

$-.35$

.51

.57

.61

.48

.64

.37

.60

.46

- 38

.42

.48

.63

.59

.54

.57

.48

.57

* Varimax rotation. In order to save space, only the positive half of the scale is listed. Factor loadings greater than or equal to 1.501 are indicated by parentheses. $N=240$. 
TABLE XI

PERCENT OF VARIANCE ACCOUNTED

FOR BY THE FOUR FACTOR ANALYSES

\begin{tabular}{|c|c|c|c|c|}
\hline \multirow{3}{*}{$\begin{array}{l}\text { Younger stimulus models/ } \\
\text { younger subjects }\end{array}$} & \multicolumn{3}{|c|}{ Factor } & \multirow[t]{2}{*}{ Total } \\
\hline & \multirow[t]{2}{*}{ A } & \multirow[t]{2}{*}{ B } & \multirow[t]{2}{*}{$\mathrm{C}$} & \\
\hline & & & & \multirow{3}{*}{49} \\
\hline $\begin{array}{l}\text { Total variance } \\
\text { Common variance }\end{array}$ & $\begin{array}{l}28 \\
57\end{array}$ & $\begin{array}{l}16 \\
33\end{array}$ & $\begin{array}{r}5 \\
10\end{array}$ & \\
\hline \multicolumn{4}{|c|}{$\begin{array}{l}\text { Younger stimulus models/ } \\
\text { older subjects } \\
\end{array}$} & \\
\hline $\begin{array}{l}\text { Total variance } \\
\text { Common variance }\end{array}$ & $\frac{31}{62}$ & $\begin{array}{l}16 \\
32\end{array}$ & $\begin{array}{l}3 \\
6\end{array}$ & 50 \\
\hline \multicolumn{5}{|c|}{$\begin{array}{l}\text { Older stimulus models/ } \\
\text { older subjects }\end{array}$} \\
\hline $\begin{array}{l}\text { Total variance } \\
\text { Common variance }\end{array}$ & $\begin{array}{l}27 \\
49\end{array}$ & $\begin{array}{l}21 \\
38\end{array}$ & $\begin{array}{r}7 \\
13\end{array}$ & 55 \\
\hline \multicolumn{5}{|c|}{$\begin{array}{c}\text { Older stimulus models/ } \\
\text { younger subjects }\end{array}$} \\
\hline $\begin{array}{l}\text { Total variance } \\
\text { Common variance }\end{array}$ & $\begin{array}{l}25 \\
50\end{array}$ & $\begin{array}{l}17 \\
34\end{array}$ & $\begin{array}{r}8 \\
16\end{array}$ & 50 \\
\hline
\end{tabular}

\section{STABILITY}

Two different indicators of factor similarity were utilized in evaluating the stability of the factors across the age levels. The first indicator was the inspection, or "eyeball", technique of comparing the scales most strongly associated with a factor in one analysis with those most strongly associated with a factor in another analysis in order to determine whether the factors would receive the same interpretation in both analyses. The second indicator consisted of the coefficients of congruence 
for the factors being compared, as suggested by Harman ( 1960 , pp. 256-259).

\section{Inspection}

Factor A. Scales involved with Factor A for each of the four factor analyses are presented in Table XII. Within both age levels of subjects, cross-age comparisons of Factor A revealed a high degree of similarity across stimulus models -only eight differences out of a possible 78 occurred. Even more than was the case with the across stimulus model age level comparisons, the across subject age level comparisons of Factor A revealed a high degree of similarity -- only four differences out of a possible 78 occurring. The cross-age comparisons of Factor A are detailed below, looking first at the cross stimulus model comparisons and then at the cross subject comparisons. Factor A, although not identical, was highly similar for the younger subjects across the two age levels of stimulus models. Seventeen scales were jointly involved in Factor A for both younger and older stimulus models for the younger subjects (Table XII, row 1, column 3). Only four scales involved in Factor A for the younger subjects were not jointly involved for both age levels of stimulus models. ${ }^{11}$ Consequently, the interpretation of Factor A for the younger subjects would be approximately the same regardless of stimulus model age.

${ }^{11}$ The four scales not jointly involved in Factor A for the younger subjects for both age levels of stimulus models were: beautiful/ugly (OY), has desire to learn/has no desire to learn (OY), honest/dishonest $(Y Y)$, and mature, understands self/immature, does not understand self $(O Y)$. 
TABLE XII

SCALES INVOLVED WITH FACTOR A

Subjects

Stimulus rodels

\begin{tabular}{lll}
\hline & Stimulus lodels \\
\hline Younger (I) & Older (2) & Both (I) and (2) \\
Pleasant & Pleasant & Pleasant \\
Understanding & Flexible & Understanding \\
Generous & Open minded & Flexible \\
Considerate & Cooperative & Considerate \\
Nice & Considerate & Cooperative \\
Cooperative & Understanding & Nice \\
Loving & Nice & Generous \\
Flexible & Nodest, humble & Open minded \\
Friendly & Friendiy & Loving \\
Has good rela- & Has good rela- & Friendly \\
tions with & tions with & Has good rela- \\
people of & people of & tions with \\
other ages & other ages & people of \\
Good & Generous & other ages \\
Non-bigoted & Loving & Modest, humble \\
Non-domineering, & Beautiful & Good \\
non-bossy & Good & Non-bigoted \\
Iylodest, humble & Non-complainer & Non-domineering, \\
Open minded & Non-domineering, & non-bossy \\
Has sense of & non-bossy & Has sense of \\
humor & Has sense of & humor \\
Honest & humor & Non-complainer \\
Non-complainer & Non-bigoted & \\
& Mature, under- & \\
& Has desire to & \\
& learn &
\end{tabular}

Younger (1)

Looper

Friendiy

tas tions with people of other ages

Good

Non-bigoted

Non-domineering. non-bossy lilodest, humble Open minded Has sense of humor

Honest Non-complainer
Pleasant Cooperative Considerate Nice Friendly tions with people of other ages Generous Loving

Non-complainer Non-domineering. non-bossy Has sense of humor

Non-bigoted Mature, understands self learn
Older (2) Cooperative Open minded Pleasant Considerate Flexible Ilodest, humble Generous Nice Has good relations with people of other ages Loving Non-complainer
Cooperative Open minded Generous Understanding Nice Considerate Pleasant Flexible Has good relations with people of other ages ivon-bigoted Loving
Cooperative Open minded Considerate Generous Pleasant Flexible Nice Has good relations with people of other ages Loving Modest, humble Understanding 
TABLE XII (CONTINUED)

Subjects

Stimulus Models

\begin{tabular}{lll}
\hline Younger (1) & Older (2) & Both (1) and (2) \\
\hline Non-domineering, Friendly & Non-bigoted \\
non-bossy & Wodest, humble & Non-complainer \\
Good & Non-complainer & Friendly \\
Friendly & Good & Good \\
Non-bigoted & Has sense of & Non-domineering, \\
Understanding & humor & non-bossy \\
Well groomed & Beautiful & Has sense of \\
Has sense of & Non-domineering, humor \\
humor & non-bossy & Beautiful \\
Honest & Has desire to & \\
Responsible, & learn & \\
reliable & & \\
Beautiful & &
\end{tabular}

$\begin{array}{cl}\text { Both (1) } & \text { Pleasant } \\ \text { and (2) } & \text { Considerate } \\ & \text { Cooperative } \\ & \text { Generous } \\ & \text { Nice } \\ & \text { Flexible } \\ \text { Loving } & \text { Understanding } \\ \text { Has good rela- } & \text { tions with } \\ \text { people of } \\ \text { other ages } \\ \text { Open minded } \\ \text { Modest, humble } \\ \text { Friendiy } \\ \text { Good } \\ \text { Non-domineering. } \\ \text { non-bossy } \\ \text { Non-bigoted } \\ \text { Non-complainer } \\ \text { Has sense of } \\ \text { humor } \\ \text { Honest }\end{array}$

Open minded

Pleasant

Pleasant

Cooperative

Flexible

Cooperative

Understanding

Considerate

Nice

Generous

Has good relations with people of

other ages

Friendly

Loving

liodest, humble

Non-bigoted

Non-complainer

Beautiful

Good

Has sense of

humor

Non-domineering,

Considerate

Flexible

Generous

Nice

Open minded

Understanding

Loving

Has good relations with people of other ages Friendly Modest, humble Non-bigoted Good

Iron-complainer Non-domineering, non-bossy

Has sense of non-bossy

Has desire to learn

* Only scales with factor loadings of 1.501 or greater are included. In order to save space, only the positive half of the scale is listed. The scales are ordered as in Table XIII. 
Factor A appeared to also be highly similar across stimulus model age levels for the older subjects. Eighteen scales were jointly involved in Factor $A$ for both the younger and older stimulus nodels (Table XII, row 2, column 3). Only four scales involved in Factor A for the older subjects were not jointly involved for both age levels of stimulus models. ${ }^{12}$ Factor A for the older subjects would, therefore, receive approximately the same interpretation for both the younger and older stimulus models.

Factor A also appeared to be highly similar across the two age levels of subjects, within both age levels of stimulus models, and would, consequently, receive approximately the same interpretation regardless of subject age. A comparison across subject ages for the younger stimulus models revealed 18 scales jointly involved in Factor A for both the younger and older subjects (Table XII, row 3, column 1). Only three scales were not jointly involved in Factor A for the younger stimulus models for both age l'evels of subjects.13. For the older stimulus models, 19 scales were jointly involved in Factor A for both the younger and older subjects (Table XII, row 3, column 2). Only one scale

12 The four scales not jointly involved in Factor $A$ for the older subjects for both. age levels of stimulus models were: has desire to learn/has no desire to learn (00), honest/aishonest (YO), responsible, reliable/irresponsible, unreliable (Yo), and well groomed/poorly groomed (YO).

${ }^{13}$ The three scales not jointly involved in Factor $\mathrm{A}$ for the younger stimulus models for both age levels of subjects were: beautiful/ugly (YO), responsible, reliable/irresponsible, unreliable (YO), and well groomed/poorly groomed (YO). 
was not jointly involved in Factor A for the older stimulus models for both age levels of subjects. 14

Thus, both the across stimulus model age level and the across subject age level comparisons provided evidence for the similarity of Factor A across ages. As a consequence, the interpretation made of Factor A for each of the four factor analyses was the same, and it was based primarily on the 17 scales jointly involved in Factor A for all four of the analyses (Table XII, row 3, column 3). An examination of these 17 scales suggested that the underlying dimension of social evaluation defined by Factor $A$ is concerned with the social aspect of personal ability -- i.e., the ability to "get along" with others. Factor A was accordingly given the descriptive name of "Interpersonal Ability . "15

Factor B. Table XIII presents the scales involved with Factor B for the four separate factor analyses. Factor B appeared to be considerably similar across both stimulus model and subject age level comparisons -- although somewhat less so than Factor A. Eleven out of a possible 49 differences occurred across stimulus model, and nine out of a possible 49 differences occurred across subject age levels. The cross-age comparisons are detailed below.

${ }^{14}$ The one scale not jointly involved in Factor A for the older stimulus models for both age levels of subjects was: mature, understands self/immature, does not understand self.

${ }^{15}$ None of the six scales mentioned above which were involved in Factor $A$ for at least one but not all four of the factor analyses -- beautiful/ugly, has desire to learn/has no desire to learn, honest/dishonest, mature, understands self/immature, does not understand self, responsible, reliable/irresponsible, unreliable, and well groomed poorly groomed -- contradicts the interpretation of Factor $\mathrm{A}$ as defining an Interpersonal Ability dimension. 
For the younger subjects, Factor B appeared highly similar across stimulus model age levels. Eleven scales were jointly involved with Factor B for the younger subjects for both the younger and older stimulus models (Table XIII, row I, column 3). Only three scales were not jointly involved for both stimulus model age levels. 16

Factor B for the older subjects, although still considerably similar, did not appear to be as similar across stimulus model age levels as it was for the younger subjects. For the older subjects, eight scales were jointly involved in Factor $B$ for both stimulus model age levels (Table XIII, row 2, column 3). Eight scales, however, were not jointly involved for both younger and older stimulus models. 17

Factor B appeared to also be considerably similar across subject age levels, perhaps more so for the older stimulus models, however, than for the younger stimulus models. Eight scales were jointly involved with Factor B for both age levels of subjects for the younger stimulus models (Table XIII, row 3 , column 1): six scales were not jointly involved in Factor $B$

16 The three scales not jointly involved in Factor B for the younger subjects for both age levels of stimulus models were: does physical exercise/does no physical exercise (YY), large/ small (YY), and non-domineering, non-bossy/domineering, bossy (OY, negative association).

17 The eight scales not jointly involved in Factor B for the older subjects for both age levels of stimulus models were: has desire to learn/has no desire to learn (00), healthy/unheal thy (00), informed about current events/uninformed about current events (00), intelligent/unintelligent $(00)$, involved in civic affairs/uninvolved in civic affairs $(00)$, mature, understands self/immature, does not understand self $(Y O)$, modest, humble/arrogant, know-it-all 100 , negative association), and non-domineering, non-bossy/domineering, bossy (00, negative association). 
for both age levels of subjects. ${ }^{18}$ For the older stimulus models, 12 scales were jointly involved with Factor $B$ for both age levels of subjects (Table XIII, row 3, column 2): only three scales were not jointly involved for both younger and older subjects. 19

Because of its similarity across ages, Factor B received the same interpretation for all four analyses. This interpretation was primarily based on the seven scales involved in Factor B for all four factor analyses (Table XIII, row 3, column 3). These seven scales appeared to be concerned with the nonsocial aspect of personal ability -- i.e., the ability to "take care of oneself." Factor B was therefore named "Instrumental Ability. "20

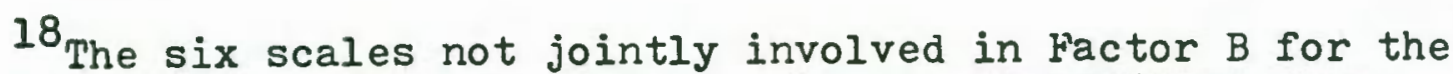
younger stimulus models for both age levels of subjects were: heal thy/unheal thy (YY), informed about current events/uninformed about current events (YY), intelligent/unintelligent (YY), involved in civic affairs/uninvolved in civic affairs (YY), large/ small (YY), and mature, understands self/immature, does not understand self (YO).

${ }^{19}$ The three scales not jointly involved in Factor $B$ for the older stimulus models for both age levels of subjects were: does physical exercise/does no physical exercise $(00)$, has desire to learn/has no desire to learn $(00)$, and modest, humble arrogant. know-it-all (00, negative association). 20 Suct Such an interpretation is not substantially contradicted by any of the 10 scales which were involved in Factor $B$ for at least one but not all four of the factor analyses -- does physical exercise/does no physical exercise, has desire to learn/has no desire to learn, healthy/unhealthy, informed about current events uninformed about current events, intelligent/unintelligent, involved in civic affairs/uninvolved in civic affairs, large/small, mature, understands self/immature, does not understand self, modest, humble/ arrogant, know-it-all (negative association), and non-domineering, non-bossy/domineering, bossy (negative association). 
TABLE XIII

SCALES INVOLVED WITH FACTOR B*

Subjects

Younger (1)

Stimulus Models

\begin{tabular}{lll}
\hline Younger (1) & Older (2) & Both (1) and (2) \\
\hline Active & Active & Active \\
Strong & Strong & Strong \\
Fast & Independent & Independent \\
Intelligent & Enthusiastic & Enthusiastic \\
Alert & Fast & Fast \\
Enthusiastic & Ambitious, hard & Alert \\
Independent & working & Ambitious, hard \\
Informed about & Healthy & working \\
current events Alert & Intelligent \\
Involved in & Involved in & Healthy \\
civic affairs civic affairs & Involved in \\
Ambitious, hard Intelligent & civic affairs \\
working & Non-domineering, Informed about \\
Large & non-bossy* & current events \\
Healthy & Informed about & \\
Does physical & current events & \\
exercise & &
\end{tabular}

Older (2)

Alert
Active
Strong
Enthusiastic
Ambitious, hard
working
Fast
Independent
Does physical
exercise
mature, under-
stands self

Active

Active

Strong

Independent

Fast

Strong

Alert

Enthusiastic

Ambitious, hard

working

civic affairs

Enthusiastic

Fast

Alert

Independent

Ambitious, hard working

Does physical

exercise

Informed about current events

Heal thy

Non-domineering, non-bossy

Has desire to learn

Does physical

exercise

Intelligent

Modest, humble** 
TABLE XIII (CONTINUED)

\begin{tabular}{|c|c|c|c|}
\hline \multirow{2}{*}{ Subjects } & \multicolumn{3}{|c|}{ Stimulus biodels } \\
\hline & Younger (I) & Older (2) & Both (1) and (2) \\
\hline $\begin{array}{l}\text { Both (1) } \\
\text { and (2) }\end{array}$ & $\begin{array}{l}\text { Active } \\
\text { Strong } \\
\text { Alert } \\
\text { Enthusiastic } \\
\text { Fast } \\
\text { Ambitious, hard- } \\
\text { working } \\
\text { Independent } \\
\text { Does physical } \\
\text { exercise }\end{array}$ & $\begin{array}{l}\text { Active } \\
\text { Strong } \\
\text { Independent } \\
\text { Enthusiastic } \\
\text { Fast } \\
\text { Ambitious, hard- } \\
\text { working } \\
\text { Alert } \\
\text { Involved in } \\
\text { civic affairs } \\
\text { Healthy } \\
\text { Informed about } \\
\text { current events } \\
\text { Non-domineering, } \\
\text { non-bossy } \\
\text { Intelligent }\end{array}$ & $\begin{array}{l}\text { Active } \\
\text { Strong } \\
\text { Enthusiastic } \\
\text { Fast } \\
\text { Alert } \\
\text { Independent } \\
\text { Ambitious, } \\
\text { hardworking }\end{array}$ \\
\hline
\end{tabular}

* Only scales with factor loadings of 1.50 ol or greater are included. In order to save space, only the positive half of the scale is listed. The scales are ordered as follows: (1) by magnitude of factor loadings; (2) by magnitude of factor loadings; and both (I) and (2) by magnitude of average factor loadings (ties are not indicated).

* Negative association with factor.

Factor C. Factor C exhibited considerably less similarity across ages than did Frctors $A$ and $B$ (see Table XIV). No scales were jointly involved with Factor $C$ for all four analyses. The only across stimulus model age level similarity which exists is for the younger subjects, and the only across subject age level similarity is for the older stimulus models. Five out of nine possible differences occurred across stimulus models, and three out of nine possible differences occurred across subjects.

looking at the across stimulus model age level comparisons for the younger subjects, two scales were jointly involved 
with Factor $C$ for both younger and older stimulus models (Table XIV, row 1, column 3) and two scales were not jointly involved. 21 For the older subjects, no scales were jointly involved with Factor $\mathrm{C}$ for both younger and older stimulus models (Table XIV, row 2, column 3), and three scales were not jointly involved. 22

For the across subject age level comparisons, no scales were jointly involved in Factor $\mathrm{C}$ across both younger and older subjects for the younger stimulus models (Table XIV, row 3 , column 1), and two scales were not jointly involved. ${ }^{23}$ For the older stimulus models, three scales were jointly involved for both age levels of subjects (Table XIV, row 3, column 2), and one scale was not jointly involved in Factor $\mathrm{C}$ for both age levels. 24

Since there were no scales jointly involved with Factor C for all four of the separate analyses, no interpretation of Factor C could be made which was applicable for all four analyses. However, on the basis of the analysis in which the most scales were

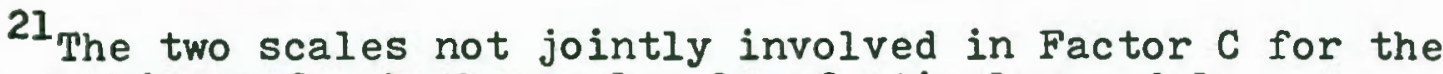
younger subjects for both age levels of stimulus models were: good/bad $(O Y)$ and honest/dishonest (OY).

22 The three scales not jointly involved in Factor $\mathrm{C}$ for the older subjects for both age levels of stimulus models were: financially careful/financially careless $(00)$, honest/dishonest $(00)$, and responsible, reliablelirresponsible, unreliable $(00)$.

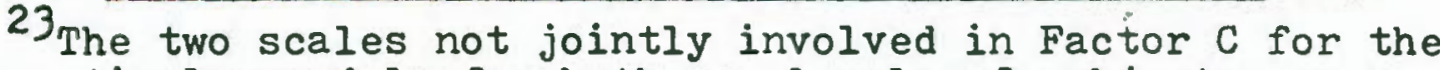
younger stimulus models for both age levels of subjects were: financially careful/financially careless (YY) and responsible, reliable/irresponsible, unreliable (YY).

24 The one scale not jointly involved in Factor $C$ for the older stimulus models for both age levels of subjects was: good/bad (OY). 
involved with Factor C -- older stimulus models/younger subjects -- Factor C was tentatively labeled a "Propriety" dimension. Since no different scales were involved with Factor $C$ for the other three analyses, the same interpretation of Factor $C$ was considered extendable to all of the analyses.

TABLE XIV

SCALES INVOLVED WITH FACTOR C

Subjects

Stimulus Models

Younger (1) Otimulus Models

$\begin{array}{ccc}\text { Younger (1) } \begin{array}{c}\text { Financially } \\ \text { careful } \\ \text { Responsible, } \\ \text { reliable }\end{array} & \begin{array}{c}\text { Responsible, } \\ \text { reliable } \\ \text { Honest } \\ \text { Financially } \\ \text { careful }\end{array} & \begin{array}{c}\text { Responsible, } \\ \text { Feliable } \\ \text { carefially }\end{array} \\ & & \text { careful }\end{array}$
Good

\begin{tabular}{cl}
\hline Older (2) & $\begin{array}{l}\text { Honest } \\
\text { Financially } \\
\text { careful } \\
\text { Responsible, } \\
\text { reliable }\end{array}$ \\
\hline Both (1) & $\begin{array}{l}\text { Honest } \\
\text { and (2) } \\
\text { Responsible, } \\
\text { reliable } \\
\text { Financially } \\
\text { careful }\end{array}$ \\
\hline
\end{tabular}

- Only scales with factor loadings of 1.501 or greater are included. In order to save space, only the positive half of the scale is listed. The scales are ordered as follows: (1) by magnitude of factor loadings; (2) by magnitude of factor loadings; and both (I) and (2) by magnitude of average factor loadings (ties are not indicated).

Similarity Percentages. The similarity percentages of the younger and older age levels of stimulus models and subjects, which provide a summary statistic for the inspection assessment of similarity, are compared in Table XV. Out of 
the 21 scales involved with Factor A for the younger subjects for one or the other of the stimulus model age levels, 17 were jointly involved for both age levels of stimulus models, and therefore the younger subjects earned a similarity percentage on Factor A of $81 \%$. Across subjects, the older stimulus models received higher similarity percentages over all three factors than did the younger stimulus models. Across stimulus models, however, the younger subjects accrued higher similarity percentages on Factors $B$ and $C$ than did the older subjects; Factor A was nearly identical for both age levels of subjects.

TABLE XV

\section{SIMILARITY PERCENTAGES}

Across Stimulus Models Younger
Subjects

Factor A Joint Scales Total Scales \% of Total

Factor B

Joint Scales Total Scales $\%$ of Total

Factor C

Joint Scales Total Scales \% of Total 17

21

81 Older Subjects

$$
11
$$$$
79
$$

18

22

82

8
16
50

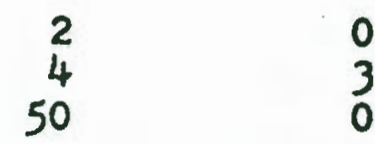

Across Subjects

Younger Sti- Older Stimulus Model mulus Model

18

21
86

19

20

95

* Similarity percentages are based on scales involved 1.501 or greater with a factor (see Tables XII - XIV). 


\section{Coefficients of Congruence}

The second indicator of similarity utilized in evaluating the stability of the factors across the two age levels was the coefficient of congruence (also called the "unadjusted correlation"). Harman (1960, pp. 257-259) suggested the use of the coefficient of congruence to assess the degree of similarity between factors. In explaining the coefficient of congruence, Harman (1960, p. 258) pointed out that:

While this formula is similar in form to the productmoment correlation .... it certainly is not a correlation -- the $a^{\prime} s$ are not deviates from their respective means and the summations are over the $\underline{n}$ variables instead of the number of individuals.... The coefficient of congruence can range in value from tl for perfect agreement (or -1 for perfect inverse agreement) to zero for no agreement whatsoever.

The coefficients of congruence for each of the three factors for the two across stimulus model age level and the two across subject age level comparisons appear in Table XVI.

TABLE XVI

COEFFICIENTS OF CONGRUENCE*

Comparison

Across subject age levels

$$
\text { OY/OO }
$$$$
\text { YYAO }
$$

.984

.979

.945

.907

Across stimulus model age levels

YO/OO

.974

.953
.956

.659

.583

* Coefficients of congruence for each factor are based on all 38 scales. 
Across Stimulus Hodel Age Level Comparisons. A comparison of Factor A across the younger and older stimulus models, within each of the two subject age levels, revealed a large degree of similarity between the factors (.974 for each within subject age level comparison). Likewise, Factor B across the younger and older stimulus models possessed a large degree of similarity (.956 for the younger subjects and .953 for the older subjects), although not quite as large did Factor A. However, Factor $C$ possessed considerably less similarity across the younger and older stimulus models than did Factors $A$ and $B$ (.583 for the younger subjects and .659 for the older subjects).

Across Subject Age Level Comparisons. Comparisons of the factors across subject age levels for each of the factors yielded similar results. Factor A for the younger and older subjects, within each of the age levels of stimulus models, maintained a large degree of similarity (.984 for the younger stimulus models and .982 for the older stimulus models). Factor B was comparably similar across subject age levels for the older stimulus models $(.979)$ and slightly less similar for the younger stimulus models (.945). Factor $\mathrm{C}$ was also quite similar across subject age levels for the older stimulus models (.907), but less similar for the younger stimulus models $(.724)$.

\section{$\underline{\text { Summary }}$}

The two methods of assessing factor similarity -- inspection and coefficients of congruence -- generally agree in their findings. Considerable stability of the semantic differential 
technique across stimulus model age and across subject age in the measurement of social evaluation was found in two of the three factors -- the two major factors. Factors $A$ and $B$ are quite similar across both subject and stimulus model age levels, with Factor A being somewhat more similar than Factor B. Factor $C$ is similar only across certain comparisons. According to the inspection method, Factor $C$ is only similar: 1) across subjects for the older stimulus models, and 2) across stimulus models for the younger subjects. The coefficients of congruence method, however, detected a large degree of similarity in only one of the four comparisons: across subject age levels for the older stimulus models. Thus, the interpretation suggested earlier for Factor $C$ shall be limited to pertaining only to the two older stimulus models analyses ( $O Y$ and 00 ).

Across subjects comparisons for the three factors are somewhat more similar than across stimulus models comparisons (except for the YY/YO comparison by the coefficients of congruence method). In addition, the older stimulus models tended to be more congruent across subjects than the younger stimulus models.

Interpretations suggested for the factors were: Factor A defines an Interpersonal Ability dimension for both age levels of subjects and stimulus models; Factor B defines an Instrumental Ability dimension for both age levels of subjects and stimulus models; and Factor $\mathrm{C}$ defines a Propriety dimension for the older stimulus models only. 


\section{INSTABILITY}

If concept-scale or subject-scale interaction occurred across age levels, one would seek evidence of the occurrence in the major differences between the two age levels. Thus, major differences occurring across stimulus models are to be suspected of reflecting tendencies toward concept-scale interaction, while major differences occurring across subjects are to be suspected of reflecting tendencies toward subject-scale interaction. In considering the instability of the semantic differential technique across age levels of subjects and stimulus models, this report looks first at the factors and then at the individual scales.

\section{Factors}

Factors $A$ and $B$, as noted by both the inspection and the coefficients of congruence techniques of assessing factor similarity, were highly similar across both subject and stimulus model age levels. Factor $C$, however, did not exhibit such crossage similarity. As will be recalled, no general interpretation of Factor $C$ could be made during the inspection assessment of similarity since no scales were jointly involved with Factor C for all four analyses. The coefficients of congruence did indicate that Factor $C$ was quite similar (.907) across younger and older subjects for the older stimulus models. Such a high level of similarity of Factor $C$ did not exist for the other across subject comparison (.724), and even less similarity existed for either across stimulus model comparison (.583 for 
the younger subjects and .659 for the older subjects). The lack of similarity of Factor $C$ across stimulus models (for both subject age levels) is to be suspected of reflecting tendencies toward concept-scale interaction, while the lack of similarity across subjects for the younger stimulus models is to be suspected of reflecting tendencies toward subject-scale interaction.

\section{Scales}

Scales which had the largest differences (.22 or greater) in their factor loadings across the two age levels of subjects or stimulus models are indicated in Table XVII. In all, 30 of the 38 scales incurred differences equal to or greater than .22 (or roughly $5 \%$ of the total variance of a scale) in their factor loadings across the four factor matrices. Such differences may be suspected of reflecting concept-scale or subjectscale interaction tendencies. Twenty-eight of the scales exhibited tendencies toward concept-scale interaction and 11 toward subject-scale interaction (nine scales are counted twice since they exhibited tendencies toward both concept-scale and subjectscale interaction). That more than twice as many of the scales with major differences reflected tendencies toward conceptscale interaction than toward subject-scale interaction is understandable in light of the earlier finding that the across subjects comparisons were generally somewhat more similar than the across stimulus models comparisons, of the 28 scales exhibiting tendencies toward concept-scale interaction, six scales incurred large differences on Factor A, nine on Factor B, and 20 on Factor C. Of the 11 scales exhibiting tendencies toward subject- 
TABLE XVII

SCALES EXHIBITING INTERACTION TENDENCIES*

Interaction

Scales

Active

Alert

Ambitious, hardworking

Beautiful

Considerate

Cooperative

Does physical exercise

Enthusiastic

Fast

Financially careful

Flexible

Friendly

Generous

Good

Has desire to learn

Has good relations with

people of other ages

Has sense of humor

Heal thy

Honest

Independent

Informed about current events

Intelligent

Involved in civic affairs

Large

Loving

iiature, understands self

hodest, humble

IVice

Nion-bigoted

Non-complainer

Non-domineering, nonbossy

Open minded

Pleasant

Responsible, reliable $\mathrm{X}$

Strong

Understanding

Well groomed

Young
Ten- Concept-Scale Subject-Scale

dency $A$ B C $A$ B C

$\mathrm{X}$

$\mathrm{X}$

X $\quad$ X

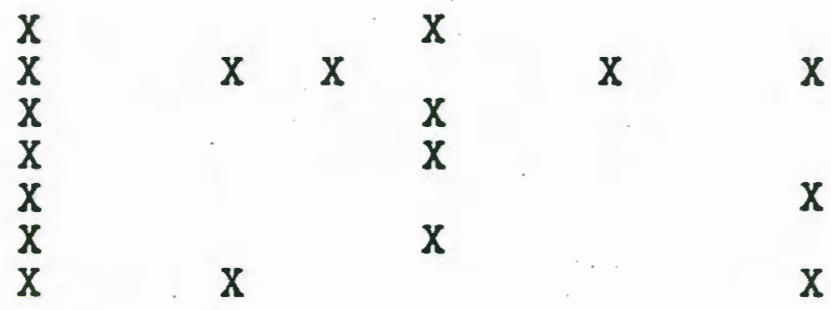

$\begin{array}{lll}X & X & \\ X & X\end{array}$

$\begin{array}{llll}\mathrm{X} & \mathrm{X} & \mathrm{X} & \mathrm{X} \\ \mathrm{X}\end{array}$

$\mathrm{X} \quad \mathrm{X}$

$\mathrm{X}$

X X

$\mathrm{X}$

X $\mathrm{X}$

$\mathrm{X}$

$\mathrm{X}$

$\mathrm{X} \quad \mathrm{X}$

$\mathrm{X}$

$\mathrm{X}$
$\begin{array}{llll}\mathrm{X} & & \mathrm{X} & \\ \mathrm{X} & & & \mathrm{X} \\ \mathrm{X} & \mathrm{X} & \mathrm{X} & \\ \mathrm{X} & & \mathrm{X}\end{array}$

$\begin{array}{lll}\mathrm{X} & \mathrm{X} & \mathrm{X} \\ \mathrm{X} & \mathrm{X}\end{array}$

* Differences across the four factor analyses equal to or greater than .22 are indicated. In order to save space, only the positive half of the scale is listed. 
scale interaction, two scales incurred large differences on Factor A, four on Factor B, and eight on Factor C. The preponderance of large differences occured on Factor $C$, as was to be expected, since Factor $C$ was not very similar over three of the four comparisons.

of special interest, then, are the unexpected differences, that is, the differences occurring on Factors $A$ and $B$-- the two stronger and more stable factors -- and those occurring across subjects on Factor $C$ for the older stimulus models. These major differences of special interest are described below, first those suspected of reflecting concept-scale interaction tendencies, and then those suspected of reflecting subject-scale interaction.

Concept-Scale Interaction Tendencies. Whether the conceptscale interaction tendencies occurred for the younger or older age level of subjects is indicated in Table XVIII. Of the seven differences suspected of reflecting concept-scale interaction tendencies for the younger subjects, three occurred on Factor A and four on Factor B. For the older subjects, nine differences suspected of reflecting concept-scale interaction tendencies occurred -- three on Factor A and six on Factor B.

Subject-Scale Interaction Tendencies. Table XIX indicates whether the subject-scale interaction tendencies occurred for the younger or older age levels of stimulus models. For the younger stimulus models, one of the differences occurred on Factor A and three on Factor B. For the older stimulus models, one of the five differences occurred on Factor $A$, one on Factor $B$, and three on Factor $C$. 
TABLE XVIII

CONCEPT-SCALE INTERACTION TENDENCIES*

Younger Stimulus Models

Younger subjects (YY/OY)

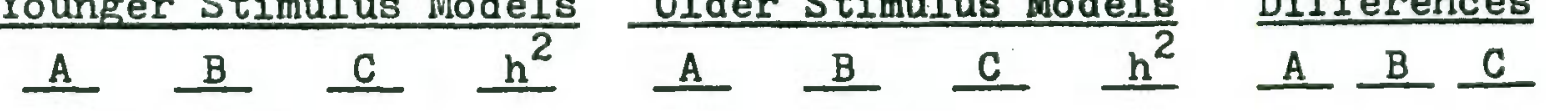

Has desire to learn*

Informed about current events

Responsible, reliable

Financially careful***

Has good relations with

people of other ages**

Large

Older Subjects ( $\mathrm{YO} / \mathrm{OO})$

Financially careful *

Honest**

Well groomed**

Informed about current

events

Involved in civic

affairs

Modest, humble

Non-domineering, non-

bossy**

$$
\begin{array}{rrrrrr}
.27 & .46 & .35 & .41 & (.53) & .42 \\
.08 & (.55) & .07 & .32 & .30 & (.51) \\
.42 & .16 & (.57) & .53 & .18 & .47 \\
.24 & -.01 & (.59) & .40 & .12 & .25 \\
(.70) & -.01 & .17 & .52 & (.67) & .23 \\
-.17 & (.53) & -.17 & .34 & .03 & .26
\end{array}
$$$$
\begin{array}{r}
.30 \\
.18 \\
.12
\end{array}
$$$$
.42
$$$$
.16
$$$$
(.51)
$$$$
\begin{array}{ll}
.51) & .03 \\
.47 & (.60
\end{array}
$$$$
48
$$$$
.26
$$

$$
.03
$$

.25

(.51)

$$
.35
$$

.31
.26

$\begin{array}{lrrrrrrrrr}.47 & .19 & .37 & .39 & .04 & .46 & (.57) & .53 & .43 & .27 \\ (.58) & .30 & .29 & .52 & .31 & .03 & (.66) & .53 & .27 & .27 \\ (.60) & .30 & .02 & .46 & .36 & .39 & .31 & .37 & .24 & \\ .02 & .35 & -.01 & .12 & .17 & (.67) & .03 & .48 & & .32 \\ .09 & .44 & -.06 & .20 & .17 & (.73) & -.03 & .56 & .29 \\ (.78) & -.25 & .04 & .68 & (.69)(-.50) & .02 & .73 & .25 \\ (.72) & -.24 & -.01 & .58 & (.55)(-.58) & -.17 & .67 & .34\end{array}$

* Only differences across factor analyses equal to or greater than .22 for Factors $A$ and $B$ are included. In order to save space, only the positive half of the scale is listed. Factor loadings greater than or equal to 1.501 are indicated by parentheses. * Difference involves shifting of largest loading from one factor to another.

**Difference involves a polarity reversal. 
TABLE XIX

SUBJECT-SCALE INTERACTION TENDENCIES *

Younger Stimulus Models

Younger Subjects

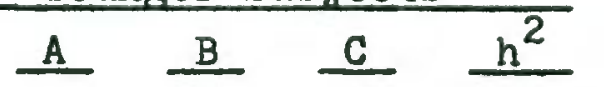

Older Subjects

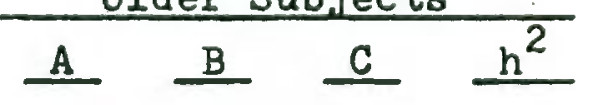

Differences

A B C $(Y Y / Y O)$

\section{Intelligent}

Large* *

Modest, humble

Financially careful

$$
\begin{array}{cccc}
.27 & (.65) & .37 & .63 \\
-.17 & (.53) & -.17 & .34 \\
(.66) & -.49 & .18 & .71 \\
.24 & -.01 & (.59) & .40
\end{array}
$$

$\begin{array}{rr}-.05 & .21 \\ .08 & .16 \\ .04 & .68 \\ .37 & .39\end{array}$

21
16
68

$.39 \quad .23$

Older Stimulus Models (OY/O0)

Responsible, reliable Non-bigoted***

Generous

Has sense of numor***

Nice

$\begin{array}{rrrr}.18 & .47 & (.60) & .61 \\ (.56) & .17 & -.17 & .38 \\ (.66) & -.01 & .36 & .57 \\ (.57) & .31 & .19 & .46 \\ (.70) & -.04 & .46 & .69\end{array}$

$\begin{array}{rrrr}.42 & .40 & (.57) & .65 \\ (.74) & -.08 & -.06 & .55 \\ (.78) & .10 & .07 & .63 \\ (.58) & .27 & -.03 & .41 \\ (.77) & .11 & .24 & .66\end{array}$

.24 .25

* Only differences across factor analyses equal to or greater than .22 for Factors $A$ and $B$, and for the older stimulus models on Factor $C$, are included. In order to save space, only the positive half of the scale is listed. Factor loadings equal to or greater than 1.501 are indicated by parentheses.

* Difference involves shifting of largest loading from one factor to another. ** Difference involves a polarity reversal. 
Interaction Tendencies on Jointly Involved Scales. Seven of the 25 major differences described above concerned those scales which were jointly involved with Factor A for both age levels of stimulus models and subjects (see Table XII, row 3, column 3). These seven scales were: generous/ selfish, has good relations with people of other ages/has poor relations with people of other ages, has sense of humor/has no sense of humor, modest, humble/arrogant, know-it-all, nice/ awful, non-bigoted/bigoted, and non-domineering, non-bossy/ domineering, bossy. None of the major differences described above concerned scales which were jointly involved with Factor $B$ for both age levels of stimulus models and subjects (Table XIII, row 3, column 3). However, all three of the scales jointly involved with Factor $C$ for the older stimulus models (Table XIV, row 3, column 2) -- financially careful/financially careless, honest/dishonest, and responsible, reliable/irresponsible, unreliable -- showed major differences.

\section{$\underline{\text { Summary }}$}

Major differences in factors or scales occurring across ages which might reflect either concept-scale or subject-scale interaction tendencies were examined. Evidence indicating interaction tendencies on the part of the factors was detected in Factor $C_{8}$ the lack of similarity across stimulus models for both age levels of subjects was suspected of reflecting 
concept-scale interaction tendencies, and the lack of similarity across subjects for the younger stimulus models was suspected of reflecting subject-scale interaction tendencies. Differences in the scales of .22 or greater across the four factor analyses were identified as possibly reflecting either concept-scale or subject-scale interaction tendencies. In agreement with the stability findings, more differences occurred across stimulus model age levels than across subject age levels, and more occurred on Factor $C$ than on Factors $A$ and B. Ten unexpected differences -- i.e., differences occurring on Factors $A$ and $B$, and on Factor $C$ for the older stimulus models -- occurred on scales jointly involved with one of the factors for the relevant age levels of stimulus models and subjects.

\section{YOUNG/OLD}

As mentioned earlier, the scale young/old was included in the study's semantic differential to provide a check on the perceived ages of the stimulus models.

It was hoped that the scores on the scale young/old would reveal that the sample of younger stimulus models was perceived by the rating subjects as substantially younger than was the sample of older stimulus models, and that, within each age level sample, the stimulus models were perceived as approximately the same age. Such were the results. 
The mean score on young/old for the younger stimulus models, averaged across both age levels of rating subjects, was 5.7; for the older stimulus models, it was 1.8 (see Figure 1). For both the younger and older stimulus models, the scale young/old had the smallest standard deviation of all the scales (.90 and .67. respectively, averaged across both age levels of rating subjects). And, the means and standard deviations for young/old did not differ meaningfully across age levels of rating subjects (see Table $\mathrm{XX}$ ). Thus, the data indicate that the stimulus models were indeed perceived by the subjects as had been intended, that is, the younger stimulus models were perceived as being young aduits and the older stimulus models were perceived as being elderly.

$$
\text { old } T_{1}^{0} \frac{}{2} \frac{}{3} \frac{Y}{5}^{Y} \frac{}{7} \text { Young }
$$

Figure 1. Niean scores of stimulus model age levels on scale young/old. Scores were averaged across both age groups of rating subjects. Older stimulus models are indicated by " $O$ " and younger stimulus models by "Y".

\section{SUMMARY}

Three factors were defined by each of the four separate factor analyses of the scales -- younger stimulus models/ younger subjects, younger stimulus models/older subjects, older stimulus models/older subjects, and older stimulus models/ 
younger subjects. Comparisons of the three factors across the four factor analyses were examined from both of the perspectives of stability and instability of the semantic differential technique across stimulus age and subject age in the measurement of social evaluation.

Factors $A$ and $B$ were found by two different methods of assessing factor similarity -- inspection and coefficients of congruence -- to be quite similar across both stimulus model and subject age levels. Consequently, Factor $A$ was interpreted as an Interpersonal Ability dimension, and Factor $B$ as an Instrumental Ability dimension, for both age levels of stimulus models and subjects. Of the two, Factor $A$ was found to be somewhat more similar than Factor B across the age levels. Factor $C$ was found to be similar only for the older stimulus models across subject age levels; consequently, the interpretation of Factor C as a Propriety dimension pertains only to the older stimulus models (for both age levels of subjects). In general, the across subject age level comparisons were somewhat more similar than the across stimulus model age level comparisons. Also, the older stimulus models tended to be more similar across subjects than were the younger stimulus models.

Major differences, or instances of instability, occurred either on Factor $C$ or on certain specific scales. More of the scale differences occurred: 1) across stimulus model age level comparisons than across subject age level comparisons, 
and 2) on Factor $C$ than on Factors $A$ and $B$. Ten unexpected differences -- i.e., differences occurring on Factors $A$ and $B$, or on Factor C for the older stimulus models -. occurred on scales identified as being jointly involved with a factor for all relevant factor matrices.

In general, however, the findings regarding instability agreed with the findings regarding stability; they are merely the other face of the coin. Thus, the large degree of similarity of Factors $A$ and $B$-- the two major factors -- supports a finding of considerable stability of the semantic differential technique across stimulus model and subject age levels in the measurement of social evaluation.

\section{TABLE XX}

MEANS AND STANDARD DEVIATIONS FOR SCALE YOUNG/OID

Stimulus Models

Younger

older

\begin{tabular}{ccccc}
\multicolumn{3}{c}{ Younger } & \multicolumn{2}{c}{ Subjects } \\
\cline { 1 - 1 } Mean & $\begin{array}{c}\text { Standard } \\
\text { Deviation }\end{array}$ & & Mean & Deviation \\
5.4 & .86 & & 6.0 & .93 \\
1.9 & .65 & & 1.7 & .68
\end{tabular}


CHAPTER IV

IMPICATIONS OF STUDY

What implications do the study findings suggest regarding the question under investigation, is it valid to utilize the same semantic differential test in investigating the social evaluation of persons of different ages? In addition to implications regarding the cross-age validity of the semantic differential technique, implications regarding two other concomitant findings of the study are also of interest. These concern: 1) the dimensionality of social evaluation, and 2) the construction of a cross-age semantic differential.

\section{CROSS-AGE VALIDITY OF THE SEMANTIC DIFFERENTIAL TECHNIQUE}

What implications do the data suggest regarding the question of whether a given semantic differential test measures the same social evaluation phenomena for different ages? specificaliy, is the test used in a qualitatively similar 26 or different manner in the rating of, or by, adults of different ages? If the semantic differential is used in a qualitatively similar manner, than the suggested conclusion would be that adults of different ages constitute one class of stimuli

26 By qualitatively similar is meant that the discrimination between various stimuli or subjects occurs on the same dimensions -- that is, the dimensions are not transformed by the nature of the stimulus or subject. 
and/or population of subjects (for the purposes of measuring social evaluation with the semantic differential technique). If it is used in a qualitatively different manner, the suggested conclusion would be that of multiple classes of stimuli and/ or of populations of subjects.

In this study, considerable stability of the semantic differential technique across two age levels of stimulus models and two age levels of subjects was found. Younger subjects (ages 22 to 32 ) evaluated the stimulus models in a qualitatively similar fashion to older subjects (ages 60 or older). And, younger stimulus models (estimated ages 22 to 32 ) were evaluated by the subjects in a qualitatively similar fashion as were older stimulus models (estimated ages 60 years and older).

of the three factors defined in each of the four separate factor analyses -- younger stimulus models/younger subjects, younger stimulus models/older subjects, older stimulus models/ younger subjects, and older stimulus models/older subjects -two factors ( $A$ and $B$ ) jointly accounted for most of the common variance. 27 Both of these factors were found by two different methods of assessing factor similarity, inspection and coefficients of congruence, to be highly similar across both stimulus model and subject age levels.

Some evidence contradicting a conclusion of qualitative sameness of younger and older adults in social evaluation activity is presented by the third factor. Factor $C$. Factor $C$

27 From $84 \%$ to $94 \%$ of the common variance in the four separate factor analyses was accounted for by Factors $A$ and $B$. 
did not prove to be as similar across stimulus model and subject age levels as did Factors $A$ and $B$; it exhibited only one cross-age similarity of any note (that of the older stimulus models across subject age levels). Thus, Factor C presents evidence of some differences existing between younger and older age levels of stimulus models and subjects. Since Factor C was only a minor factor 28 however, its lack of stability across the four analyses poses a warning about rather than a rejection of a conclusion of cross-age sameness.

Thus, the conclusion suggested by the data is that younger and older adults, both as stimuli and as subjects, are approximately the same qualitatively in social evaluation activities (although not identical), and consequently, that the semantic differential technique is quite stable across younger and older age levels of adult stimuli and subjects in the measurement of social evaluation. This finding of considerable stability of the semantic differential technique across younger and older adult stimuli and subject age levels -- if it can be generalized to all adult age levels -- possesses implications for both the utilization and the construction of semantic differential tests to be used to measure social evaluation across ages.

\section{Utilization Implications}

The stability finding suggests that a semantic differential

28 Factor $C$ accounted for from $6 \%$ to $16 \%$ of the common variance in the four separate factor analyses. 
teat designed to measure social evaluation may be constructed which will be valid across adult stimuli ages and across adult subject ages. Thus, it should not be necessary to construct separate tests for different age levels of adult stimuli nor for different age levels of adult subjects. This implication is of some practical importance, because such generally valid tests are considerably more efficient than separate tests in the making of cross-age comparisons.

Complications for the suggestion of cross-age validity of the semantic differential technique, however, may be created by the cohort phenomenon. Because of the changing experiential history of the population, a cross-age semantic differential valid today might not remain valid in the future. In that case, as cohorts move through the life span, new cross-age semantic differentials to measure social evaluation would have to be constructed, or perhaps, no such cross-age semantic differential would even be possible.

\section{Construction Implications}

The stability finding also suggests that a reasonably valid semantic differential test designed to measure social evaluation can probably be developed under less than optimal conditions. Optimally, it would be preferable to construct a semantic differential out of scales jointly involved with the relevant factor for all of the age levels, i.e., out of scales whose factor loadings lie above the researcher's pre-determined cut-off level for all age levels to be studied. However, a 
test constructed of scales involved with the factors for only one of the age levels -- for example, as was the case with the subjects in the Rosencranz and McNevin (1969) Aging Semantic Differential -- should probably not be too invalid. Similarly. a test constructed of scales involved with the factors for pooled age levels -- for example, as was the case with the stimuli in the Aging Semantic Differential -- should probably also not be too invalid. Under both of the above conditions, however, some scales may be included in the resulting semantic differential tests that are not jointly valid for all age levels to be studied.

\section{DIMENSIONS OF SOCIAL EVALUATION}

\section{The Dimensions}

Three dimensions of social evaluation were defined by the current study -- an Interpersonal Ability dimension (Factor A) and an Instrumental Ability dimension (Factor B) for both younger and older stimulus models and subjects, and a Propriety dimension (Factor $C$ ) for the older stimulus models (for both age levels of subjects). Scales involved 29 with the Interpersonal Ability dimension include: pleasant/unpleasant, cooperative/uncooperative, and considerate/inconsiderate; while active/ passive, strong/weak, and enthusiastic/unenthusiastic are examples of scales involved with the Instrumental Ability dimension. The scales honest/dishonest, responsible, reliable/

${ }^{29}$ Scales considered to be"involved" with a factor are those with loadings of 1.501 or greater. 
irresponsible, unreliable, and financially careful/financially careless were involved with the Propriety dimension. 30

Interpersonal Ability, Instrumental Ability, and Propriety, then, were the dimensions of social evaluation represented by the 38 scales included in the study. It is to be anticipated that additional, or altered, dimensions of social evaluation will be specified in other studies utilizing different samples of stimuli and scales. However, if the history of the EPA factor structure for general stimuli -- i.e., the recurrent findings of the major factors and the occasional findings of minor factors for different samples of stimuli and scales -repeats itself for the factor structure for persons as stimuli, one could expect the Interpersonal Ability and Instrumental Ability dimensions (or variations thereof) to prove to be among the major dimensions of social evaluation. That is, one could expect the Interpersonal Ability and Instrumental Ability dimensions to define major dimensions of social evaluation not just for younger and older adults, but for adults of all ages.

Comparisons with other Studies

Comparisons of the current attitudinal dimensions with dimensions from other semantic differential studies revealed considerable similarity. Two comparisons were made -- one with the 1957 Osgood et al. studies from which standard reference

${ }^{30} \mathrm{All}$ scales involved with the Interpersonal Ability, Instrumental Ability, and Propriety dimensions for at least one of the age levels of stimulus models and subjects were listed in Tables XII, XIII, and XIV, respectively. 
scales were derived for this study, and a second with the Rosencranz and McNevin 1969 study of attitudes towards the aged.

of the three factors -- Evaluation, Potency, and Activity -repeatedly defined in studies by Osgood and his colleagues (1957), the current Interpersonal Ability dimension appears most similar to Evaluation, while the Instrumental Ability dimension appears to be a combination of Potency and Activity (such a combination is sometimes called a "Dynamism" factor). Indeed, two of the three standard reference scales selected to represent Evaluation in the current study -- good/bad and nice/ awful -- were involved with the Interpersonal Ability dimension for all four factor analyses, and the remaining scale -- beautiful/ugly -- was involved with the Interpersonal Ability dimension for three of the four analyses ( $Y O, 00, O Y$ ). Of the two standard reference scales selected to represent Potency in the current study, one -- strong/weak -- was involved with the Instrumental Ability dimension for all four factor analyses, while the other -- large/small -- was involved with the Instrumental Ablitity dimension for one of the four analyses (YY). Both of the two standard reference scales selected to represent Activity -fast/slow and active/passive -- were also involved with the Instrumental Ability dimension for all four factor analyses. Only one of the standard reference scales -- good/bad -- was involved with another factor than was specified above; good/bad, in addition to being involved with the Interpersonal Ability dimension for all four factor analyses, was also involved with 
the Propriety dimension for one of the analyses (OY). Thus, agreement between the Evaluation and Interpersonal Ability dimensions and between the Dynamism and Instrumental Ability dimensions suggests that the specification of the two major dimensions of social evaluation in the current study was not just a chance happening. The traditional EPA factor structure does differ from the current study's factor structure, however, in that it was defined for stimuli in general, while the current dimensions were defined for a restricted set of stimuli, i.e.. persons.

A comparison of the current study with the 1969 study of Rosencranz and McNevin is of the utmost relevance since the two studies dealt with similar samples of scales and stimuli. In a factor analysis of a large but unspecified number of scales ${ }^{31}$ used in the rating of three age levels of males (20 to 30 years, 40 to 55 years, and 70 to 85 years), Rosencranz and McNevin defined three major attitudinal dimensions -Instrumental-Ineffective, Autonomous-Dependent, and Personal Acceptability-Unacceptability. Scales forming Rosencranz and McNevin's Instrumental-Ineffective dimension included active/ passive, strong/weak, expectant/resigned, productive/unproductive, and busy/idle. Among the scales included in the AutonomousDependent dimension were independent/dependent, secure/insecure, organized/disorganized, and certain/uncertain. 32

31 At least 32 scales were included in the Rosencranz and MicNevin study.

32 The Autonomous-Dependent dimension was later reinterpreted by another researcher as a Decisive-Indecisive dimension (Naus, 1973). 
The Personal Acceptability-Unacceptability dimension included such scales as pleasant/unpleasant, cooperative/uncooperative. flexible/inflexible, generous/selfish, tolerant/intolerant, and Iriendly/unfriendy.

As can be seen, Rosencranz and McNevin's Personal Acceptability-Unacceptability dimension is very similar to the current Interpersonal Ability dimension. Likewise, their Instrumental-Ineffective dimension is very similar to the current Instrumental Ability dimension -- both apparently combine the general dimensions of Potency and Activity into one Dynamism type of dimension. However, the two studies differ on the Autonomous-Dependent dimension of the Rosencranz and MicNevin study and on the Propriety dimension of the current study. The only scale associated with Rosencranz and McNevin's AutonomousDependent dimension which was also included in the current study -independent/dependent -- was involved with the Instrumental Ability dimension in the current study. None of the scales involved with this study's Propriety dimension were included in the Rosencranz and McNevin study. Thus, insufficient information exists at the present time to determine the status of the two non-agreeing dimensions of social evaluation. However, the agreement of Rosencranz and McNevin's Personal Acceptability-Unacceptability dimension with the current Interpersonal Ability dimension, and that of Rosencranz and McNevin's Instrumental-Ineffective dimension with the current Instrumental Ability dimension, provide further evidence that the 
study's major two dimensions of social evaluation were not specified by chance.

III. CONSTRUCTION OF A CROSS-AGE SEMANTIC DIFFERENTIAI

A cross-age semantic differential to measure social evaluation was constructued from scales identified as being applicable across ages. A comparison of the resulting CrossAge Semantic Differential with Rosencranz and McNevin's Aging Semantic Differential revealed several significant differences.

\section{Scales Applicable Across Ages}

As will be recalled, 24 scales were jointly involved with the dimensions of Interpersonal Ability and Instrumental Ability for both age levels of stimulus models and subjects -17 scales with the Interpersonal Ability dimension (see Table XII, row 3, column 3), and seven scales with the Instrumental Ability dimension (see Table XIII, row 3, column 3). Three scales were involved with the Propriety dimension (see Table XIV, row 3, column 2), which was defined for the older stimulus models only (for both age levels of subjects). Of these 27 scales, however, 10 scales $^{33}$ exhibited large differences $(.22$ or greater) in their factor loadings across age levels of stimulus models or subjects. Such large differences were suspected

33 The ten scales exhibiting large differences in their factor loadings across age levels of stimulus models or subjects were: financially careful/financially careless, has good relations with people of other ages/has poor relations with people of other ages, has sense of humor/has no sense of humor, honest/dishonest, generous/selfish, modest, humble/arrogant, know-it-all, nice/awful, non-bigoted/bigoted, non-domineering, non-bossy/domineering, bossy, and responsible, reliable/irresponsible, unreliable. 
of reflecting concept-scale or subject-scale interaction tendencies. Seven of these scales were jointly involved with the Interpersonal Ability factor, and their large differences all occurred in loadings on the Instrumental Ability or Fropriety (OY/O0) factors. The remaining three scales were involved with the Propriety factor for the older stimulus models, and their large differences occurred on the Interpersonal Ability and Instrumental Ability factors. That is, all of the large differences occurred on factors with which the scales were not jointly involved. However, since none of the scales are purely associated with only one factor, i.e., the score on a scale identified as being involved with a particular factor is also partially attributable to other factors, the safe course to follow in constructing a semantic differential would be to avoid scales which exhibit such large differences whenever possible. Thus, the 10 scales were removed from the list of scales to be considered for inclusion in the cross-age semantic differential test being constructed. The final listing of scales - 10 on Interpersonal Ability and seven on Instrumental Ability -- identified as applicable for measuring social evaluation across younger and older age levels is presented in Table XXI.

\section{A Cross-Age Semantic Differential}

A semantic differential test for measuring social evaluation across younger and older age levels of stimuli and subjects, constructed of jointly applicable scales, is propozed 
in Figure 2.34 Fifteen scales are included in the proposed test, seven scales represent each of the Interpersonal Ability and Instrumental Ability dimensions of social evaluation and one scale -- young/old -- is included as a check on the perceived ages of the stimuli. The first seven scales listed in the proposed Cross-Age Semantic Differential represent the Interpersonal Ability dimension, and the second seven scales represent the Instrumental Ability dimension. Average factor loadings (i.e., averaged across all four factor analyses) for the scales representing the Interpersonal Ability dimension ranged from .72 through .80 ; scales representing the Instrumental Ability dimension averaged factor loadings of from .64 to .79. All of the scales representing each factor averaged factor loadings of less than .25 on the non-represented factor.

A test such as the proposed Cross-Age Semantic Differential has considerable versatility of application. It can be used for a single subject or for a group of subjects. It can be used to compare subjects or stimuli, or both. The comparisons can be made for a given time or over time. The ratings can be of the self or of others. And, the ratings can be actual or projected (i.e., how the subject thinks someone else would rate the stimuli). Such a test might find application in the study of sources (such as different prior experiences) and/or of the consequences (such as adjustment to stage ${ }^{34}$ In application, the order of scales in the Cross-Age Semantic Differential would be randomly determined, as would be the direction of the scales (positive to negative, or negative to positive), so as to minimize the likelihood of response bias tendencies on the part of the subjects. 


\section{TABLE XXI}

\section{SCALES APPLICABLE ACROSS AGES*}

\section{Interpersonal Ability}

Pleasant (.80)

Cooperative (.79)

Considerate (.77)

Flexible (.77)

Open minded $(.76)$

Understanding (.75)

Loving $(.72)$

Friendly (.71)

Good $(.65)$

Non-complainer (.64)
Instrumental Ability

Active (.79)

Strong (.76)

Enthusiastic (.69)

Fast $(.67)$

Alert (.67)

Independent (.66)

Ambitious, hardworking $(.64)$

- In order to save space, only the positive half of the scale is listed. Factor loadings averaged over all four factor analyses are indicated in parentheses.

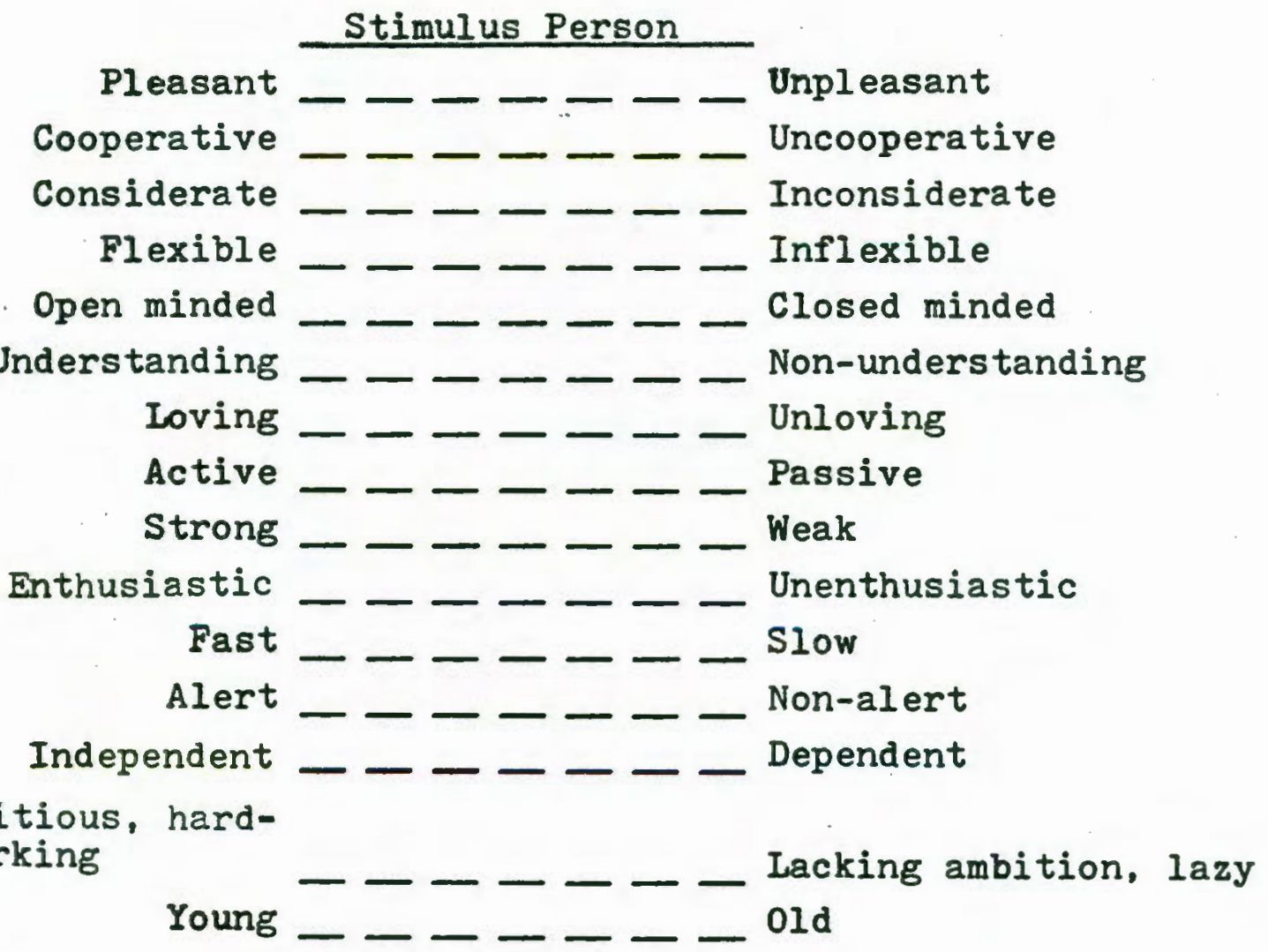

Figure 2: Cross-age semantic differential for social evaluation. 
of life cycle or approach-avoidance tendencies toward people of certain ages) of differentially held social evaluations of people across or within younger and older age levels. Of special utility may be the application of the Cross-Age Semantic Differential in the study of the image of younger and older people on television -- since, unlike many instruments designed to measure attitudes toward people of different ages, this test was developed using images of actual people (i.e., the videotaped stimulus models) and not on verbal symbols (e.g., "a person 22 to 32 years of age" or "a person 60 years of age or older").

Comparison with the Aging Semantic Differential

The proposed Cross-Age Semantic Differential differed in its construction from the 1969 Rosencranz and McNevin Aging Semantic Differential in several ways. However, these differences can not be completely determined because the methods of the Rosencranz and McNevin study were not clearly reported. A comparison, based on the available information, is presented below: it is organized by the four general aspects of methods of the semantic differential technique -- scale selection. stimuli selection, data collection, and data analysis (see Table XXII).

Scale Selection. Rosencranz and MicNevin (1969, p. 55) generated their list of adjectives from subjects "of all ages" (however, the actual age breakdown was not reported); and their generating subjects "were asked to list bipolar sets of 
adjectives descriptive of attributes or behavioral characteristics of persons of all ages." In contrast, the generating subjects in the current study consisted of two specific age levels -- 22 to 32 years of age and 60 years of age and older -and they were requested to list bipolar adjective pairs describing persons of those same two ages. The sex ratio of the generating subjects in the Rosencranz and McNevin study was not reported (although it could be determined that at least some of the subjects were female), nor was the sex of the generating stimuli. In the current study, equal numbers of males and females formed each of the two age levels of generating subjects, and each subject generated adjectives concerning persons only of the subject's own sex. Also, in the current study, the generating subjects were requested to provide equal numbers of positive and negative descriptions; whether this was the case for the Rosencranz and McNevin study was not reported. Stimuli Selection. In the Rosencranz and McNevin study, three age levels of stimuli to be rated on the scale were utilized -- 20 to 30 years, 40 to 55 years, and 70 to 85 years -while in the current study two age levels of stimuli were utilized -- 22 to 32 years and 60 years or older. Males only were utilized as stimuli in the Rosencranz and McNevin study, whereas equal numbers of males and females were utilized in the current study. Whether the stimuli were replicated or not was not reported for the Rosencranz and McNevin study; in the current study, two replications of each of the four basic stimulus 


\section{TABLE XXII}

AGING SEMANTIC DIFPERENTIAL YS. CROSS-AGE SEMANTIC DIFPERENTIAI

\section{Scale Seleotion}

Age of generating subjects

Age of generating Btimul1

Sex of generating subjects

Sex of generating stimuli

Attributes requested -positive or negative

Stimuli Selection

Age of stimull

Sex of stirouli

Replications of stimul1

Type of stimuli

Data Collection

Age of subjects

Sex of subjects Number of scales

Data Analysis

Pactor analysis

Number of factors Pactor loadings

Crose-age differences in factor loadinge

\section{Aging Semantic Differential}

"all ages" ( $n=?)$

"all ages"

Not specifled (some female)

Not specifled

Not specifled

(1) 20 to 30 yeare, (2) 40 to 55 years, (3) 70 to 85 years Males

Not specilled

Symbols

17. to 21 years $(n=200)$

Not speclfied Not-speclfled (at least 32)

Pooled across etimull age levels Separate for each age level of

\section{Three}

Not specifled

Not specified stimulus models (and subjects)

Cross-Age Semantic Differential

(1) 22 to 32 years $(n=30)$, and (2)

60 years or older $(n=30)$

(1) 22 to 32 years, and (2) 60 years or older

Equal numbers of males and females

Subjects described own sex Equal numbers of positive and negative attributes requested

(1) 22 to 32 years, (2) 60 years or older

Equal numbers of males and females Two each of the four basio models Stimulus models

(1) 22 to 32 yaars $(n=60)$, and (2) 60 years or older $(n=60)$ Equal numbers of males and females 38 ( 30 from generating subjects) Two

(1) Interpersonal Ability scales .72 to .80 , and (2) Instrumental Ab111ty scales .64 to .79 (averaged across four analyses) 
models were utilized (i.e., two older females, two older males, two younger females, and two younger males). The stimuli consisted of symbols for the Rosencranz and McNevin study and of stimulus models for the current study. Data Collection. The list of bipolar adjective pairs was reduced to the final instrument in the Rosencranz and McNevin study by factor analysis of the ratings of one age level of subjects -- people 17 to 21 years of age $(n=200)$, while the adjective pairs in the current study were reduced to a final listing of scales applicable across adult ages by factor analysis of the ratings of two age levels of subjects -people 22 to 32 years of age $(n=60)$ and people 60 years of age or older $(n=60)$. Again, the sex ratio of the rating subjects was not reported by Rosencranz and McNevin; both age levels of rating subjects in the current study were composed of equal numbers of males and females. Apparently, although the original number of bipolar adjective pairs was not reported, more adjective pairs were subjected to rating and subsequent factor analysis in the Rosencranz and McNevin study then in the current study. In the current study, the 30 top frequency generated adjective pairs plus eight other scales were used in the rating of the stimulus models prior to factor analysis. Data Analysis. The factor analysis of the scales in the Rosencranz and McNevin study was pooled across stimulus age levels, whereas in the current study separate factor 
analyses were performed for each age level of stimulus models and subjects. In the Aging Semantic Differential, three factors are represented by the scales; the loadings of the scales on the factors were not reported. Two factors are represented in the Cross-Age Semantic Differential; their loadings ranged from .72 to .80 and from .64 to .79 . Whether scales forming the Aging Semantic Differential differ in their factor loadings across ages of subjects or stimuli is unreported; scales in the Cross-Age Semantic Differential have cross-age differences of less than .22.

Conclusions. It appears that, on the whole, the Aging Semantic Differential, although perhaps possessing a broader age basis, was developed primarily as a measure of young people's attitudes toward males of different ages. In contrast, the Cross-Age Semantic Differential, although perhaps possessing a more specific age basis, was developed primarily as a measure of cross-age attitudes toward people of both sexes of different ages. In addition, the Aging Semantic Differential was developed on ratings of symbols while the Cross-Age Semantic Differential was developed on ratings of stimulus models. Also, scales exhibiting tendencies toward concept-scale and subject-scale interaction were not included in the Cross-Age Semantic Differential, while the extent of inclusion of such scales in the Aging Semantic Differential remains unknown. It is suggested that these differences point 
to greater validity on the part of the Cross-Age Semantic Differential in the measurement of social evaluation across ages of adult subjects and/or stimuli than is possessed by the Aging Semantic Differential.

\section{SUMMARY}

This study has resulted in findings bearing upon three separate yet interrelated areas: 1) the cross-age validity of the semantic differential technique; 2) the underlying dimensionality of social evaluation; and, 3) the construction of a cross-age semantic differential test. All three of these findings are qualified by the limitations of the study, and must therefore be entertained with a certain degree of caution. In order to make a more definitive statement concerning the problem, further evidence must be sought to either support or contradict the current findings.

The study's data suggest thats 1) older and younger adults constitute qualitatively approximately the same class of stimuli, and 2) older and younger adults constitute qualitatively approximately the same population of subjects. That is, an absence of any appreciable amount of concept-scale and subject-scale interaction was observed. Such a finding contains implications regarding both the utilization and construction of semantic differential tests. In the utilization of semantic differential tests to measure social evaluation across 
ages, the data suggest that the same test can be used for stimuli and for subjects of different ages. That is to say, it will be possible to standardize a test across ages; thus, different tests will not have to be constructed for each age level of stimuli and/or subjects to be studied. Furthermore, in the construction of semantic differential tests to measure social evaluation across ages, the data suggest that tests constructed on the basis of less than all of the age levels to be studied can still be adequately valid (although it would be preferable to base the test on all of the age levels to be studied so as to be able to delete scales exhibiting tendencies toward concept-scale or subject-scale interaction).

As a concomitant to the task of investigating the stability of the semantic differential technique in the measurement of social evaluation across ages, three dimensions of social evaluation were identified, two of which -- Interpersonal Ability and Instrumental Ability -- exhibited considerable replicability across two other independent studies. In the two comparisons made: 1) Interpersonal Ability appeared to be similar to Osgood et al.'s Evaluation factor, while Instrumental Ability appeared to be similar to the Dynamism factor (a combination of Osgood et al.'s Potency and Activity factors); and 2) Interpersonal Ability appeared to be similar to Rosencranz and McNevin's Personal Acceptability-Unacceptability factor, and Instrumental Ability to their Instrumental- 
Ineffective factor (no parallel across the two studies occurred for the current study's Propriety factor nor for Rosencranz and McNevin's Autonomous-Dependent factor).

Because of the stability of the scales involved with the major two dimensions across age levels of adult stimulus models and subjects, and because of the replicability of the major two dimensions across other independent semantic differential studies, it seemed appropriate, as a capsulization of the entire study's findings, to suggest a semantic differential test for the measurement of social evaluation across ages. Consequently, a 15-scale Cross-Age Semantic Differential test was proposed. Seven scales -- pleasant/unpleasant, cooperative/uncooperative, considerate/inconsiderate, flexible/ inflexible, open minded/closed minded, understanding/nonunderstanding, and loving/unloving -- were selected to represent the Interpersonal Ability dimension of social evaluation. Another seven scales -- active/passive, strong/weak, enthusiastic/unenthusiastic, fast/slow, alert/non-alert, independent/. dependent, and ambitious, hardworking/lacking ambition, lazy -were selected to represent the Instrumental Ability dimension. And one additional scale -- young/old -- was included as a check on the perceived ages of the stimuli. This semantic differential test is suggested, on the basis of the study findings, as being appropriate to measure social evaluation (on the two dimensions of social evaluation which it represents) across ages of adult stimuli and subjects. As such, 
the Cross-Age Semantic Differential summarizes the study's findings.

To the study's inquiry of whether the semantic differential technique remains stable across age levels of adult stimuli and/or subjects in the measurement of social evaluation, then, the data suggest an answer of "Yes." Adults of different age levels appear to constitute both one class of stimuli and one population of subjects for these purposes. Thus, it appears that a semantic differential test can indeed be constructed to measure social evaluation across age levels of adults. 


\section{A SELECTED BIBLIOGRAPHY}

Antonucci, Toni

1974 "On the Relationship Between Values and Adjustment in 0ld Men." International Journal of Aging and Human Development, 5, 57-69.

Atchley, Robert C.

1972 The Social Forces in Later Lifes An Introduction to Social Gerontology. Belmont, Californias Wa.dsworth.

Back, Kurt W.

1971 "Transition to Aging and the Self-Image." Aging and Human Development, 2, 296-304.

Bell, Bill D., and Gary G. Stanfield

1973 "Chronological Age in Relation to Attitudinal Judgments: An Experimental Analysis." Journal of Gerontology, 28: $491-496$.

Birren, James E. (ed.)

1959 Handbook of Aging and the Individual. Chicagos University of Chicago Press.

Breytspraak, Iinda M., and George L. Maddox

1974 "Stability and Change in the Self-Concept in the Middle and Later Years." Presented at the 27 th Annual Scientific Meeting of the Gerontological Society, Portland, Oregon.

Brown, Roger $W$.

1958 "Is a Boulder Sweet or Sour?" Contemporary Psychology, 3: 113-115.

Bynner, John, and David Romney

1972 "A Method for Overcoming the Problem of ConceptScale Interaction in Semantic Differential Research." British Journal of Psychology, 63: 229-234.

Cain, Jr., Leonard D.

1967 "Age Status and Generational Phenomena، The New Old People in Contemporary America." Gerontologist. 7. 83-92.

1968 "Aging and the Character of Our Times." Gerontologist, $8,250-258$. 
Carroll, John B.

1959 "The Measurement of Meaning (a review)." Language. 35: 58-77.

Cryns, Arthur G., and Abraham Monk

1972 "Attitudes of the Aged Toward the Young: A Multivariate Study in Intergenerational Perception." Journal of Gerontology, 27: 107-112.

1973 "Attitudes Toward Youth as a Function of Adult Age: A Multivariate Study in Intergenerational Dynamics." International Journal of Aging and Human Development, 4: 23-33.

Darnell, Donald $\mathrm{K}$.

1966 "Concept Scale Interaction in the Semantic Differential." Journal of Communication, 16:104-115.

1970 "Semantic Differentiation," in Philip Emmert and william D. Brooks (eds.), Methods of Research in Communication. Boston: Houghton Mifflin.

Dawes, Robyn M.

1972 Fundamentals of Attitude Measurement. New York: John Wiley.

Denmark, Florence L, Ethel J. Shirk, and Robert T. Riley

1972 "The Effect of Ethnic and Social Class Variables on Semantic Differential Performance." Journal of Social Psychology, 86: 3-9.

Eisdorfer, Carl, and John Altrocchi

1961 "A Comparison of Attitudes Toward 01d Age and Mental Illness." Journal of Gerontology, 16. 340-343.

Gordon, Susan K., and W. Edgar Vinacke

1971 "Self- and Ideal Self-Concepts and Dependency in Aged Persons Residing in Institutions." Journal of Gerontology, 26: 337-343.

Gulliksen, Harold

1958 "How to Make Meaning More Meaningful." Contemporary Psychology, 3, 115-119.

Guptill, Carleton S. 1969 "A Measure of Age Identification." Gerontologist.
9: 96-102. 
Harman, Harry Horace

1960 Modern Factor Analysis. Chicagos University of Chicago Press.

Heaps, Richard A.

1972 "Use of the Semantic Differential Technique in Research: Some Precautions." Journal of Psychology, $80,121-125$.

Heise, David R.

1969 "Some Methodological Issues in Semantic Differential Research." Psychological Bulletin, 72, 406-422.

1970 "The Semantic Differential and Attitude Research," in Gene F. Summers (ed.), Attitude Measurement. Chicago \& Rand McNally.

Kaiser, Henry F.

1958 "The Varimax Criterion for Analytic Rotation in Factor Analysis." Psychometrika, 23, 187-200.

Klemmack, David I, and John A. Ballweg

1973 "Concept-Seale Interaction with the Semantic Differential Technique." Joumal of Psychology, $84.345-352$.

Kogan, Nathan, and Michael A. Wallach

1961 "Age Changes in Values and Attitudes." Journal of Gerontology, 16:272-280.

Komorita, S.S., and Alan R. Bass

1967 "Attitude Differentiation and Evaluative Scales of the Semantic Differential." Journal of Personality and Social Psychology, 6, 241-244.

Kreps, Juanita M.

1971 Iifetime Allocation of Work and Income. Durham, North Carolina: Duke University Press.

Kubiniec, Cathleen M., and S. David Farr

1971 "Concept-Scale and Concept-Component Interaction in the Semantic Differential." Psychological Reports, 28, 531-541.

Levy, Phillip

1972 "Concept-Scale Interaction in Semantic Differential Research. Solutions in Search of a Problem." British Journal of Psychology, 63: 235-266. 
MeGinnies, Elliot

1970 Social Behavior: A Functional Analysis. Boston: Houghton Mifflin.

Naus, Peter J.

1973 "Some Correlates of Attitudes Towards Old People." International Journal of Aging and Human Development. 48 229-243.

Nehrke, Milton F.

1974 "Actual and Perceived Attitudes Toward Death and Self Concept in Three-Generational Families." Presented at the 27 th Annual Scientific Meeting of the Gerontological Society, Portland, Oregon.

Neugarten, Bernice I. (ed.)

1968 Middle Age and Aging. Chicago: University of Chicago Press.

Nunnally, Jum C.

1961 Popular Conceptions of Mental Health: Their Development and Change. New York \& Holt, Rinehart, Winston.

Osgood, Charles E.

1952 "The Nature and Measurement of Meaning." Psychological Bulletin, 49: 197-237.

1953 Nethod and Theory in Experimental Psychology. New York: Oxford University Press.

1971 "Exploration in Semantic Space: A Personal Diary." Journal of Social Issues, $27: 5-64$.

Osgood, Charles E., and Ross Stagner

1941 "Analysis of a Prestige Frame of Reference by a Gradient Technique." Journal of Applied Psychology, 25: 275-290.

Osgood, Charles E., and George J. Suci

1952 "A Measure of Relation Determined by Both Mean Difference and Profile Information." Psychological Bulletin, 49: 251-262.

Osgood, Charles E., George J. Suci, and Percy H. Tannenbaum 1957 The Measurement of Meaning. Urbana, Illinois: University of Illinois Press. 
Presly, A.S.

i969" "Concept-Scale Interaction in the Semantic Differential and its Implications for Factor Scores." British Journal of Psychology, 60: 109-113.

Reed, Thomas R.

1972 "Connotative Meaning of Social Interaction Concepts: An Investigation of Factor Structure and the Effects of Imagined Contexts." Journal of Personality and Social Psychology, 24:306-312.

Rosenbaum, Leonard L., William B. Rosenbaum, and Elliot McGinnies

1971 "Semantic Differential Factor Structure Stability Across Subject, Concept, and Time Differences." Multivariate Behavioral Research, 6: 451-469.

Rosencranz, Howard A. and Tony E. McNevin

1969 "A Factor Analysis of Attitudes Toward the Aged." Gerontologist, 9, 55-59.

Ryder, Norman B.

1965 "The Cohort as a Concept in the Study of Social Change." American Sociological Review, 30, 843-861.

1968 "Cohort Analysis," in David I. Sills (ed.), International Encyclopedia of the Social Sciences, Vol.2. New York: Free Press.

Seltzer, Mildred M., and Robert C. Atchley

1971 "The Concept of Old, Changing Attitudes and Stereotypes." Gerontologist, 11: 226-230.

Smith, Raymond G.. and Harold J. Nichols

1973 "Semantic Differential Stability as a Function of Meaning Domain." Journal of Communication, 23: 64-73.

Snider, James G., and Charles E. Osgood

1969 Semantic Differential Technique. Chicago: Aldine.

Stagner, Ross, and Charles E. Osgood

1941 "An Experimental Analysis of a Nationalistic Frame of Reference." Journal of Social Psychology. 14: 389-401.

1946 "Impact of War on a Nationalistic Frame of References I. Changes in General Approval and Qualitative Patterning of Certain Stereotypes." Joumal of Social Psychology, 24: 187-215. 
Tanaka, Yasumasa, Tadasu Oyama, and Charles E. Osgood 1963 "A Cross-Culture and Cross-Concept Study of the Generality of Semantic Spaces." Journal of Verbal Learning and Verbal Behavior, 2, 392-405.

Taylor, Howard F.

1971 "Semantic Differential Factor Scores as Measures of Attitude and Perceived Attitude." Journal of Social Psychology, 83: 229-234. 